IZA DP No. 7258

Fifty Years of Compositional Changes in U.S. Out-Migration, 1908-1957

Costanza Biavaschi

February 2013 


\title{
Fifty Years of Compositional Changes in U.S. Out-Migration, 1908-1957
}

\section{Costanza Biavaschi}

$I Z A$

\author{
Discussion Paper No. 7258 \\ February 2013
}

\author{
IZA \\ P.O. Box 7240 \\ 53072 Bonn \\ Germany \\ Phone: +49-228-3894-0 \\ Fax: +49-228-3894-180 \\ E-mail: iza@iza.org
}

\begin{abstract}
Any opinions expressed here are those of the author(s) and not those of IZA. Research published in this series may include views on policy, but the institute itself takes no institutional policy positions. The IZA research network is committed to the IZA Guiding Principles of Research Integrity.

The Institute for the Study of Labor (IZA) in Bonn is a local and virtual international research center and a place of communication between science, politics and business. IZA is an independent nonprofit organization supported by Deutsche Post Foundation. The center is associated with the University of Bonn and offers a stimulating research environment through its international network, workshops and conferences, data service, project support, research visits and doctoral program. IZA engages in (i) original and internationally competitive research in all fields of labor economics, (ii) development of policy concepts, and (iii) dissemination of research results and concepts to the interested public.
\end{abstract}

IZA Discussion Papers often represent preliminary work and are circulated to encourage discussion. Citation of such a paper should account for its provisional character. A revised version may be available directly from the author. 
IZA Discussion Paper No. 7258

February 2013

\section{ABSTRACT \\ Fifty Years of Compositional Changes in U.S. Out-Migration, 1908-1957}

Immigration authorities have seldom collected data on the out-migration of the foreign-born. As a consequence, several indirect approaches have been proposed to measure and study out-migration. This paper adds to the literature by using official statistics that directly identify the out-migration by demographic and socio-economic characteristics. Using time series and panel methods on the composition of U.S. out-migration between 1908 and 1957, the paper asks two questions. First, how did the out-migrants compare with in-migrants and permanent settlers? Second, did the economic and political events of the 1900s have any impact on the composition of this outflow? Results show that the out-migrants were primarily unskilled workers, but selection has become more positive over time. The economic and political shocks of the first half of the 20th century impacted the composition of the outflow, however, the more restrictive immigration policies have been associated primarily with longer stays. These findings complements the results based on indirect measures of out-migration, and are interestingly in line with analyses of out-migrant selectivity and impact of border controls on out-migrant behavior in later periods.

JEL Classification: F22, J61, N12, K37

Keywords: return migration, out-migration, self-selection, quotas

Corresponding author:

Costanza Biavaschi

IZA

P.O. Box 7240

53072 Bonn

Germany

E-mail: biavaschi@iza.org 


\section{Introduction}

Understanding how out-migrants compare with permanent settlers and respond to evolving economic and political contexts is consequential for several lines of research: the composition of the outflow of migrants must be considered from the host country's perspective to correctly assess immigrant progress and determine the desirability of forms of short-term mobility; however, the type of migrant returning to the country of origin will also determine the gains made - and costs incurred-by the source country.

Despite its importance, studying out-migration poses serious challenges to scholars, primarily owing to the absence of systematically collected data on migrant outflows. Consequently, much remains unknown in terms of basic questions such as how sizable out-migration is, let alone more involved questions such as who the out-migrants are, how they compare with permanent stayers, and how the out-migrant composition responds to short-term shocks and adjusts over longer periods. ${ }^{1}$

Owing to the lack of data, the demographic and economic research on out-migration have relied upon indirect approaches, such as residual methods (e.g. Warren and Peck, 1980), source country-specific surveys inquiring about return migration (e.g. Massey, 1987), and the use of longitudinal datasets of permanent settlers in the host country, where out-migration enters as a form of panel attrition $(\mathrm{Hu}, 2000$, Lubotsky, 2007, Abramitzky et al., 2011).

This paper adds to the existing literature by using largely unexplored official statistics collected by the U.S. immigration authorities that allows first-hand observation of outmigrants' characteristics over a period of 50 years. Accordingly, this information provides the first direct evidence on out-migration from the U.S. to third countries, where such a flow is consistently measured every year, is not confounded with panel attrition, nor is source country-specific, and is available for several decades. Consequently, it provides a check on, and a complement to, the various research designs routinely used to study out-migration. In addition, the lengthy coverage allows an analysis of selectivity in migration flows that is consistent over many decades, providing insight as to whether reported findings in the literature differ according to economic conditions or research methodology. Finally, the data can be used to assess the impact of economic and political shocks on the composition of this outflow.

Using totals by demographic and socio-economic characteristics of the out-migrants, published in annual reports by the Bureau of Immigration during 1908-1957, the paper first describes how migrants were selected compared to the in-migrants and the permanent stayers. It subsequently assesses the impact of economic and political shocks on the composition of this outflow.

There are two main results. First, despite out-migrants being much more likely to be engaged in unskilled occupations compared to the in-migrants and the permanent stayers, selection has become more positive over time. While the out-migration of predominantly unskilled workers confirms the findings based on panel and survey datasets for shorter periods and specific countries, the progressively more positive selection of the outflow over the decades could not have been detected in earlier research approaches. Against the backdrop of decreasing immigrant quality during the 20th century (Hatton and Williamson, 2004), such a pattern is

\footnotetext{
${ }^{1}$ For instance, despite consensus that the Great Recession of the late 2000s reduced immigration flows to the U.S. from Mexico, it is debatable whether return-migration flows to Mexico have dropped, increased or even remained unchanged in response to this substantial macroeconomic shock (Rendall et al., 2011).
} 
interestingly consistent with standard theoretical models of out-migration (Borjas and Bratsberg, 1996).

The second main result is that the economic and political shocks of the first half of the 20th century impacted the composition of the outflow. In particular, restrictive immigration policies have had the sole consequence of increasing the immigrants' length of residence in the U.S. Accordingly, the conclusion that making it harder to re-enter the U.S. if one leaves makes immigrants less likely to out-migrate is consistent with findings from the studies of border enforcement, which have similarly found tougher border controls to lengthen stays (Thom, 2010, Angelucci, 2012)

The paper is organized as follows. The next section presents the existing theoretical and empirical approaches to study out-migration. Section 3 provides the historical background for this study, while Section 4 discusses the data employed. Section 5 analyzes the selection process of the out-migrants, namely who they were and how they compared with the in-migrants. Section 6 looks for structural changes in outmigrant characteristics and estimates their timing. Section 6 focuses on the impact of the quota imposition on out-migration composition, before Section 8 concludes with some observations and remarks.

\section{Theory and Evidence on Out-migration}

A number of studies have theoretically analyzed the different motivations that might drive out-migration (Dustmann and Weiss, 2007, for an overview). ${ }^{2}$ Ultimately, the decision to out-migrate in all such models hinges on the cost of migration, wage outcomes in the home and host countries, and preferences for consumption at home. These elements might not be constant across individuals: for example, costs could decrease with migrant demographics or with social ties in the destination country. In one trip-models of temporary migration, the cost of migration is also positively associated with time spent in the host country, given that the higher the cost of the trip, the longer it will take the migrant to recoup this cost (e.g. Djajifà and Milbourne, 1988). Similarly, wage outcomes in the host country could vary by demographics, increasing with time abroad and changing depending on the migrant network size (Patel and Vella, 2007, McKenzie and Rapoport, 2010). Variation in economic and social costs and benefits will affect the outmigration incentives of certain groups of migrants, and consequently how they are selected compared with the permanent stayers. Borjas and Bratsberg (1996) show that if immigrants were originally less skilled than the non-movers at home, the out-migrants will be the most successful of these migrants, based upon the notion that immigrants with the lowest skill level will always find it optimal to stay permanently in the U.S., while the most skilled immigrants might receive higher returns by out-migrating. Therefore, the theory predicts that in the case of an originally negatively selected immigration flow, the marginal out-migrant will be positively selected compared with the stayers (Borjas and Bratsberg, 1996).

While the empirical analyses of out-migration have been challenged by a lack of data on foreign-born outflows, several approaches have attempted to overcome such limitation. For instance, demographers have gauged the size of out-migration often relying on residual methods applied on post-censal population estimates, or matching methods based on other sources (e.g. Warren and Peck, 1980, Jasso and Rosenzweig,

\footnotetext{
${ }^{2}$ The literature often focuses on return migration, which differs from out-migration regarding the extent to which out-migrants move to third countries rather than moving back home. In this paper, almost all out-migrants were returning migrants, and therefore I use the conceptualization of return migration and out-migration interchangeably.
} 
1982, Van Hook et al., 2006), with all such strategies depending on how accurately the various population components and residual non-follow up are measured. Economists have studied out-migration either by relying on surveys enquiring about out-migration behavior in the source country or constructing panel datasets in the host country to capture the permanent settlers. While survey estimates are very common in the literature, ${ }^{3}$ the primary shortcoming of such approach lies in its inability to capture the overall flow from the host country. With a few exceptions, survey sources do not interview the migrants who have not returned back home, and thus analyses are unable to compare the out-migrants and the immigrants. On the other hand, panel estimates allow analyses beyond specific bilateral flows, yet need to convince that out-migration is not confounded with other sources of panel attrition. However, matching rates for the construction of the panel are around $80 \%$ in the studies based on late-1900s data, with lower rates exactly among recent immigrant arrivals, where out-migration is more likely (Lubotsky, 2007). Concerns of this type are even more pressing in historical studies on the late-1800s and early-1900s, where panels obtained by linking Census enumerations have matching rates of only around 15\% (Ferrie, 2004, Abramitzky et al., 2011).

This paper adopts a different strategy. The first (and only) systematic collection of data on out-migration from the U.S. began with the Immigration Act of 1907, whereby all vessels leaving the U.S. were required to provide passengers lists of outgoing permanent migrants to the collectors of customs. This data were collected until 1957, and published in the Annual Reports of the immigration authority (Bureau of Immigration, later called Immigration and Naturalization Services - INS). Like all other sources, the INS data has their own long-recognized limitations (for example, Jerome, 1926, Willcox, 1929, Kuznets and Rubin, 1954, Hutchinson, 1958, Kraly, 1998). Owing to the failure of customs collectors to forward passengers lists to the Department of State, and the subsequent failure of the latter to include all the passengers in the annual reports, Bandiera et al. (2012, BRV henceforth) have argued, based on residual methods applied to the universe of migrants entering New York, that the official INS records underestimate the inflows between 1910 and 1920 by as much as $18 \%$, and the outflows by a factor of $75 \%$ to $100 \%$. However, the complex accounting exercises of these authors produce negative out-migration rates for up to $40 \%$ of the nationalities in the sample, raising questions as to whether measurement error similarly affects their results. While the reader should bear this qualification in mind, Table 1 compares the INS statistics with the rates in BRV for the decade of 1910-1920. Indeed, compared to BRV, underreporting in the INS series of the outflows appears substantial, with the INS records showing an overall out-migration rate one third of that shown by these authors. Moreover, measurement differences vary with migrants' characteristics, with the discrepancy less pronounced for male migrants aged 14-44, and substantial variability by nationality. Bearing in mind that the INS Reports do not present outflows by place of birth but rather by "race or people", differences are more marked for German, British and Irish migrants (the 'old' migrants), while the outflow rate of the 'new' migrants is even larger than reported by BRV. Given this variability by nationality, we could conjecture that the authorities had different incentives to measure old and new migrants, and expect the outflows

\footnotetext{
${ }^{3}$ The empirical studies on out-migration focus both on the European experience, using national surveys conducted in source countries such as Germany (Constant and Massey, 2003), Albania (De Coulon and Piracha, 2005), Hungary (Co et al., 2000), Ireland (Barrett and O'Connell, 2000), Romania (Ambrosini et al., 2011) and the U.S. context. Here, the studies usually focus on U.S.-Mexico migration (e.g. Lindstrom and Massey, 1994, Massey, 1987, Reagan and Olsen, 2000, Lacuesta, 2010, Reinhold and Thom, 2011, Ambrosini and Peri, 2012)
} 
from Southern and Eastern Europe to be less subject to measurement error compared with outflows from Northern Europe.

To summarize, it appears that no research method prevails over the other and the use of a multiplicity of techniques holds potential for expanding our understanding of outmigration (Kraly, 1998). Given the challenges faced by the literature, the INS series provides scholars with a unique alternative route to study out-migration in a way that complements the existing strategies. While limitations have been explained above, the potentials of this source have been briefly mentioned in the introduction, and are at least threefold.

First, out-migration in this data is not confounded with other forms of nonrandom matches, nor is it indirectly obtained by residual estimates.

Second, these series span a total length of 50 years, capturing outflows over time and thus pointing to compositional changes in response to changing economic and political conditions.

Third, the topic of out-migration during and beyond the Age of Mass Migration warrants scholars' attention. While currently policy makers push forms of temporary migration as triple-win solutions for the host country, the sending country and the migrants themselves (GCIM, 2005, COM, 2007, IOM, 2007), forms of temporary migration have existed since the early 1900s and were furthermore highly debated, as explained in the next section and with dramatic consequences regarding our perception of immigration to the U.S.

The official statistics remain the sole - yet unexplored- source of direct information on foreign-born outflows, particularly beyond the National Origin Quota Act of 1924. In light of the paucity of records on the demographic and socio-economic characteristics of in-migrants and out-migrants, as well as the interest in these details over several decades, this paper provides a contribution to the understanding of these phenomena.

\section{Out-Migration in the First Half of the 1900s}

A heated debate in the political arena on the predominance of temporary migration among the new immigrant arrivals from Southern Europe commenced towards the end of the 1800s:

Generally speaking, the class of immigrants who have lately been imported and employed in the coal regions of this country, are not such, in the opinion of the committee, as would make desirable inhabitants of the United States. They are of very low order of intelligence. They do not come here with the intention of becoming citizens, their whole purpose being to accumulate by parsimonious, rigid and unhealthy economy, sums of money and then return to their native land. They live in miserable sheds like beasts, the food they eat is so meagre, scant, unwholesome and revolting that it would nauseate and disgust an American workman, and he would find it difficult to sustain life upon it. Their habits are vicious, their customs are disgusting and the effects of their presence here upon our society is to be deplored. They have not the influences, as we understand them, of a home; they do not know what the word means, and in the opinion of the committee, no amount of effort would improve tho moral standing of this class of immigration. They have been brought here in such numbers and have 
been employed at such low wages that it has resulted in their replacing the American citizens who formerly performed this class of labor until now there are comparatively few Americans engaged in mining coal in Pennsylvania.

(United states, 50th Congress, 2nd Session, 1889, House Report No. 3792, To Regulate

Immigration.)

The press of the time was similarly alarmed by the predominance of temporary migration, labeling out-migrants as the peasants rehabilitating Europe with American money, reacting to economic dumps by "scurrying off like a flock of sheep when a strange dog comes into their pasture" (The New York Times articles: Europe taking its annual toll on America, Dec. 8, 1907). The Dillingham Commission, appointed in 1907 to study the origins and repercussions of immigration to the U.S., confirmed that many immigrants at the turn of the 20th century did not regard their stay as as permanent (Dillingham Commission, vol. 1, p. 42).

Scholarly research has corroborated these facts, pushing out-migration at the center stage for that period. Evidence in Bandiera et al. (2012) supports the presence of a substantial two-way flow between the U.S. and the sending countries, with such movements having had profound implications for the measurement of immigrant assimilation and the understanding of the impact of immigration on the U.S. labor markets. Indeed, using panel data analyses, Abramitzky et al. (2011) reveal that the out-migrants were relatively less skilled than the permanent stayers, and thus prior work on immigrant assimilation in the 1910 and 1920 had been biased by the existence of such selective out-migration. ${ }^{4}$ Biavaschi (2013) shows that the presence of out-migration had an impact on local labor markets, by releasing the competitive pressure on existing workers during the 1930s and 1950s.

While a few studies have used the INS statistics, to the best of my knowledge out-migration has only been analyzed by Jerome (1926) and Gemery (1994). These authors show that out-migration appears to have been anti-cyclical, and driven more by the outflow of male immigrants than female immigrants. In terms of occupational groups, the emigrant group of laborers and farmers reported the largest drop during slumps, and little increase during booms. Gemery (1994) reported that all nationalities reacted to the Great Depression by departing from the U.S. during the interwar period, with the largest shift experienced by Mexican farm workers, whose out-migration was often promoted by U.S. state and local agencies. However, while these contributions are noteworthy, they do not address the questions and time frame explored by this paper, nor do they capture the phenomenon during the full period of the available data. Accordingly, much remains unknown on who out-migrated and how out-migration changed over time, during and beyond the Age of Mass Migration.

\footnotetext{
${ }^{4} \mathrm{~A}$ similar conclusion of negative selection is also found in the studies on out-migration during the 1970 s until to the $1990 \mathrm{~s}$ (e.g. Hu, 2000, Lubotsky, 2007).
} 


\section{Data}

The INS Annual Reports provide information on the number of in-migrants and out-migrants by sex, age, and occupation for 1908-1957. ${ }^{5}$ For $1908-1932$, I also collected outflows by race for the characteristics mentioned and for length of stay in the U.S. ${ }^{6}$

Figure 1 shows inflows and outflows between 1908 and 1957. Between 1908 and 1924 the U.S. admitted on average more than 600,000 aliens per year, with more than 200,000 out-migrating in the same period. Figure 2 show the outflow rate over the same time period. In the first half of the 20th century, the outflow ratio averaged around $30 \%$, albeit with considerable variation over the years. Indeed, the high volatility of this series has long been recognized (e.g. Jerome, 1926, Willcox, 1929). In particular, two phenomena are noteworthy: the large outflow of aliens in the years after World War I, and the huge drop in the ratio from 1921 onwards. In fact, as shown in the figures, the outflow ratio peaked to around $90 \%$ after World War I, and dropped to only $10 \%$ in the mid-1920s. Among others, Jerome (1926) suggested that the large increase in the out-migration ratio was attributable to a late recovery of immigration after the conflict and the increase in out-migration due to the economic downturn of 1920, as well as the probable postponement of the decision to return, owing to the conflict. After 1924, the restrictions imposed on in-migration appear to have reduced the outflow of aliens to a greater extent than their inflow. Indeed, following the passing of the Immigration Act of 1924, immigration never reached the peaks of the pre-war period, with out-migration experiencing a declining trend until the late-1950s, with the exception of the 1930s (Figure 3b). This behavior is remarkable, with two main reasons conjectured for the evolution of these series. First, the strong restrictions posed by the Quota Law of May 1921 and the Immigration Act of 1924 could have not only curtailed immigration until the adoption of the Preference System, but also caused this downturn in out-migration owing to the fear of being unable to return to the U.S. or have other household members arriving in the U.S. (Gemery, 1994, Hatton and Williamson, 2005). Second, economic push and pull factors undoubtedly changed in the late 1920s, with the decline in the U.S. economy and Europe's more generous formal and informal social insurance possibly having reduced incentives to in-migrate to the U.S. and increased incentives to out-migrate. Furthermore, besides the U.S., the sending economies themselves also imposed barriers on movements, which increased the costs of international migration and created new alternative destinations for migration (Gemery, 1994, Hatton and Williamson, 2005).

Building on the existing literature, this paper compares the outflows and inflows of migrants based on demographic and occupational characteristics during 1908-1957. This draws attention to the question of the overall self-selection in this flow, and particularly for the years between 1924 and $1957 .^{7}$ In an ideal

\footnotetext{
${ }^{5}$ These reports are not widely available. Therefore, academicians have relied on Willcox (1929) for the statistics published until 1924. Summaries of immigration statistics from 1829 to the present are also available in Carter et al. (2006). For the period of interest, these statistics compile all official data on the inflows of migrants and their characteristics by age, sex, and occupational status. Willcox (1929) reported similar information on the outflow of migrants, yet the early publication of his work impeded its collection between 1924 and 1957. For these decades, I employed data directly from the INS Annual Reports, which are available until 1932. From 1933 to 1940 summaries of the INS's work appeared in the Annual Report of the Secretary of Labor. For 1941, the INS Report was published in the Annual Report of the Attorney General, while no report was published in 1942 . From 1943 to 1957, the INS published its reports in mimeographed form (Hutchinson, 1958).

${ }^{6}$ The tables report flows by "race or people", which seems to correspond more to a concept of ethnicity or nationality in today's terms.

${ }^{7}$ To my knowledge, only Suzuki (1995) used the INS data to study the selectivity return migrants between 1920 and 1940 ,
} 
setting, direct information would be collected on a cohort of immigrants to the U.S. interviewed over time, with the out-migrants followed across U.S. borders. In such a context, we could observe the characteristics of those who decide to out-migrate and compare them with the characteristics of the stayers. However, in reality such an exercise is impossible with the INS report and current data sources.

Owing to these challenges, this paper will present two comparisons in the next section. First, it will compare out-migrants with in-migrants. The INS reports allow a full comparison between incoming and outgoing migrants, as used in previous literature to study the similarities of these flows (Jerome, 1926, Kuznets and Rubin, 1954, Gemery, 1994). Juxtaposition of in- and out-migrants can highlight interesting patterns over time and effects on the U.S., but the out-migrants might not be comparable to the new incoming migrants. A more sound comparison group would be made by those migrants in the arrival cohort of the current out-migrants. While the INS report contain no such information on this group, the Census - made available through the Public Use Microdata Series - can be used to focus on the stock of permanent settlers with similar length of stay in the host country. This last group was constructed by restricting the length of stay in the U.S. to the ten years prior the Census enumeration, with such a restriction derived from the observation that the INS tables report on average that more than $80 \%$ of the out-migrants had a maximum length of permanence of ten years. However, it was only possible to apply this definition for 1910-1930. In fact the 1940 and the 1950 Censuses did not ask about the year of migrant arrival. Hence, the full stock of immigrants is kept in the comparison group for these two enumerations, and the reader thus should treat substantial changes in these two later decades with caution.

\section{Out-Migrants by Sex, Age and Occupation}

Tables 2 and 3 show the sex, age and occupational distribution for outgoing migrants, compared with the in-migrants and the stock of immigrants who have been in the U.S. for a maximum of ten years.

In Table 2, the outflow of migrants for 1908-1957 appears to be characterized by a higher percentage of males, mostly between 14 and 44 years old, and working as laborers. Therefore, it initially seems that the outflow is negatively selected compared to the inflow. However, let us examine these traits in further detail.

Sex. For 1908-1957, Table 2 shows that while both flows were characterized on average by a large male component, this was even more so for migrant outflow. Figure 3 shows the outflow to inflow ratio by sex, with the percentage of outgoing male migrants consistently above the percentage of outgoing female migrants for most of this period. Figure 4 shows the sex distribution over time for incoming and outgoing migrants, highlighting the prevalence of out-migration as a male phenomenon and the different sensitivity of the two sexes to the cycle. Male out-migration peaked in 1915, 1919, 1922, and then again in 1932 and 1945, and in fact, the number of out-going migrants overtook the number of incoming migrants for these years (Figure $3 b$ ). Therefore, it seems that male migration reacted to the two wars and to the new migration restrictions to a greater degree than female migration, most likely driven by family re-conjunction. As the

but he focused on Japanese migrants alone, finding that return migrants were negatively selected. Therefore, improvement in their occupational position after World War II was simply due to selectivity. The evidence provided in this paper is in line with these results, as well as with those of the literature cited herein. 
overall outflow of migrants stabilized to around $10 \%$ of the inflow over time, the outflow-inflow ratio also stabilized for both sexes in the 1950s at around the same rate. Accordingly, it seems that the motives to return may have become more similar for males and females towards the end of the analyzed period, as can also be seen in Figure 4, where the increasing feminization of both migration and out-migration is suggestive of changes in outflow composition.

How are the out-migrants different from the stock of permanent stayers of their arrival cohort? Table 3 reiterates that out-migrants are more likely to be males than the stayers, with out-migration becoming less selective on gender over time.

The previous patterns suggest that the decisions governing in- and out-migration in the early 1900 s were very different across genders, with males appearing to have reacted more strongly to economic opportunities and political conditions than females. Over time, the shares of outgoing females and males to the share of incoming migrants were similar. Meanwhile, the sex ratios of the out-migrants compared to the permanent stayers have also converged. Given that females might have been less likely to be part of the labor force, out-migration withdrew working individuals from the market, and particularly during the Great Depression. However, given the similarities in the sex composition and reduction in the volatility of the flows in the 1950s, self-selection of out-migrants might have been less important in determining the labor market outcomes of the immigrants.

Age. While Table 2 shows that out-migrants were older on average than in-migrants, whether selective out-migration played a role in terms of migrant age can be more effectively deciphered by considering Figure 5, which shows the compositional changes over time within the migration category. There are a few peculiarities when comparing inflows and outflows.

First, the inflow and the outflow of people of prime age (14-44 years old, from our data) were remarkably similar and exhibited very little variation over time. Second, the outflow of young individuals (aged below 14 years) was rather stable, with a single peak after the war, while the inflow of younger immigrants exhibited a growing trend over time. Third, the number of migrants aged 45 years or more doubled from 1916 onwards, while the number of incoming migrants in the same category increased, although the latter seems to have stabilized at around $8 \%$ of the total inflow.

Table 3 compares the age distribution of the out-migrants with that of the stayers, highlighting similar trends: migrants are predominantly individuals of prime age, although out-migration seems to involve a lager flow of older individuals over time. However, compared to the stayers, out-migration in the first half of the 20th century appears to have predominantly involved a flow of young workers, hence probably withdrawing productive sources from the labor market.

Occupation. A brief inspection of Table 2 shows that out-migrants held low skilled occupations, and were $28 \%$ more likely than in-migrants to be laborers.

However, a few concerns emerge while interpreting this information. First, these results might be driven by the inaccuracy in the reporting of occupations across the two groups, although the INS reports indicate that these unreported occupations were mostly those of children and women. 
Second, it is unclear whether the data reports the actual occupation of the in-migrants or rather their anticipated occupation in the U.S. Indeed, Ferrie (1999) noted how certain occupational groups, such as farmers, tended to report their potential occupation rather than their occupation at origin. Even if prospective occupations in the U.S. were reported (assuming that immigrants were eventually employed in that specific sector), the out-migrants would be unskilled workers compared to the in-migrants.

Third, if the reported occupations were those held in the country of origin, the comparison would not be meaningful. Early reports of the Immigration Commission, and their elaboration by Bloch (1921) showed that most immigrants employed in the agricultural sector in their country of origin ended up working in the mining and manufacturing sectors in the U.S. Therefore, occupational mobility while in the U.S. could seriously distort the comparison between in and out-migrants. Ferrie (1999) showed considerable downward mobility from white collar to unskilled and from skilled to unskilled jobs, with the Irish reporting the worst outcome. Accordingly, in this third scenario, we need to be more cautious before drawing conclusions concerning out-migrant selectivity.

When studying occupational characteristics it appears particular important to look for a comparison between the occupations of the stock of permanent settlers and the out-migrants with a similar length of stay in the host country. Moreover, when studying occupations, I additionally restrict attention to male workers, given that the INS data does not report female occupation.

Table 3 compares the the occupational distribution for the stock of immigrants enumerated in the Census and the outflow of migrants. ${ }^{8}$ For the most of the period under analysis out-migrants were more likely to be laborers and less likely to work in skilled occupations and in agriculture. However, there might be other confounding factors driving this pattern, and particularly concerns that immigrant occupational mobility and shifts in sending countries may invalidate the conclusions.

The INS Annual Reports of 1910, 1920, 1930 and 1950 classify the occupations of incoming and outgoing migrants by "race or people". ${ }^{9}$ Despite conditioning on both place of birth and length of stay is impossible in the data, we can nonetheless exploit the fact that most out-migration occurred within 10 years of arrival. Figure 6 compares the occupational distribution of outgoing Italians and Russians with the occupational distribution of the stock of Italians and Russians present in the U.S. who had immigrated 10 years prior the Census enumeration. This comparison also allows us to check whether problems of measurement are driving the descriptive results, given that the out-migration rate of Russian migrants seems to be more similar across data sources (Table 1). Using data on Russian or Italian out-migrants and conditioning on the length of stay in the country yields similar conclusions: out-migrants were primarily negatively selected in the early-1900s, although selection became more positive in the mid-1900s, despite a relatively stable occupational distribution of the stock of permanent settlers.

To summarize, regardless of whether the official data reports information on prospective occupations or whether we consider occupational mobility, out-migrants were more likely to have had unskilled jobs than in-migrants. Despite the secular changes in the U.S. productive structure, as shown by the decreasing number of people engaged in agriculture, the trends are more marked for out-migrants than in-migrants.

\footnotetext{
8 The Census categories have been classified to resemble the INS categories.

${ }^{9}$ The INS Annual Report of 1940 does not provide such information. Therefore, this particular Census year was not considered in the analysis.
} 
Accordingly, the outflow of people in the first half of the twentieth century was largely characterized by laborers and servants, and immigrant stayers were not equally likely to be employed in such jobs.

These results confirm the findings on selective Japanese return migration by Suzuki (1995) and on negative selection achieved by Abramitzky et al. (2011). In line with the theory (Borjas and Bratsberg, 1996), the aforementioned patterns indicate that the progressive drop in immigrant quality over the 1900s (Hatton and Williamson, 2004) was followed by increasing positively selected out-migration flows. Indeed, as would be expected from evolving costs and benefits of migration, the selection of out-migrants does not appear to be a stable process.

\section{Long-Term Structural Changes in Out-Migrant Composition}

The previous section highlighted changes in the composition of the migrant outflow, and particularly showed a secular change in the sex composition, progressive aging of the out-migration flow, and an increase in the number of out-migrants engaged in skilled occupations over time. While these patterns could be driven by a secular trend, they could also be subject to particular economic and political shocks causing important breaks in the outflow composition. Accordingly, this section further explores these phenomena by allowing the data to identify the presence of structural breaks that could relate to the many dramatic events of the first few decades of the 1900s. This allows us to understand how out-migration behaves over time. For instance, if a break is detected after the Great Depression, with an increase in the number of out-migrants with particular characteristics, we could deduce that substantial macroeconomic shocks - such as those of recent years - have a (non-transitory) strong effect on out-migration.

This section focuses on comparing shifts in the sex, age (14-44 years old versus others) and occupational composition of skilled versus unskilled out-migrants. ${ }^{10}$ The comparison between compositional changes in these series before and after a specific event would rely on the assumption that the researcher knows the precise timing of the occurrence and its effects. While certain events of the 1900s could be specifically dated (e.g., the wars), without looking at the data it is much less clear whether the same can be achieved for other occasions. For example, despite the common perception that the U.S. suddenly closed its borders in 1924, in reality the change in the immigration policy was a slow process that started with Literacy Act in 1917, followed by the Immigration Act of 1921, and finally culminating with the quotas of 1924 (Hatton and Williamson, 2005). Furthermore, even if specific dates were available, anticipation effects might play an important role in even shifting the composition of the outflow before such dates. The timing of the eventual breaks could be determined by looking at the data, but such a procedure would violate the exogeneity of the timing. Finally, we cannot rule out ex ante the possibility of multiple breaks rather than a single shift in the data generating process.

Therefore, I apply standard techniques developed in the macroeconomic literature to locate and test the presence of structural changes in the composition of migrant outflow. I consider the following model:

$$
S_{t}^{c}=\beta_{0}+\beta_{1} T+\varepsilon_{t}^{c},
$$

\footnotetext{
${ }^{10}$ Skilled $=$ Professionals and Skilled occupations; Unskilled $=$ Laborers and farmers
} 
where $S_{t}^{c}$ is the share of out-migrants with characteristic $c$ at time $t$ and $T$ is a linear trend. Given the numerous shocks in the first fifty years of the 1900s, the regression coefficients might not be stable over time. Bai and Perron $(1998,2003)$ use a test based on the residual sum of squares from the equation above, estimated for a segment starting at observation $t$ and ending at $t^{\prime}$ with $t<t^{\prime}$. Through this methodology, it is possible to test for zero versus $l$ breaks, with an arbitrary yet fixed $l$. I follow Bai (1997) in creating confidence intervals around the break date.

This technique allows us to be agnostic on which events might have affected the flow. Therefore, we can test whether the main events of the 1900s had structural effects on average out-migrant characteristics, or rather if they simply consisted of transitory shocks on these series. Table 4 and Figure 7 reports the main analysis, with the former showing the detected breaks with relative confidence intervals, and the compositional changes in the average shares in the different subperiods. Meanwhile, Figure 7 shows the breakpoint dates and their confidence intervals.

The previous section highlighted that despite the prevalence of out-migration as a male phenomenon, over time, we see a 'feminization' of this flow over time. Figure 7(a) and Table 4 report one break in this series, corresponding to 1927 , and associated to a drop in the fraction of males leaving the country, i.e. a $20 \%$ change in the average share of out-going males. This change might be associated with the implementation of the new immigration restrictions, but is estimated rather imprecisely with a confidence interval that covers the entire 1930s, and hence also the Great Depression period.

Figure 7(b) shows the ratio of individuals aged 14-44 years leaving the U.S. between 1908 and 1957 with relative breaks, while Table 4 reports the size effects of such changes. Unlike the sex composition, the age structure of outgoing migrants has been subject to two breaks, in 1917 and in 1944. The first period corresponds to the beginning of the World War I, its aftermath and the early-1920s. Indeed, it is unsurprising that the war was associated with a reduction in out-migration of individuals in prime age, given that they were likely to have been affected by the conflict. Indeed, the conflict seems to have shifted the age distribution of outgoing migrants toward its extremes, with such change corresponding to a $15 \%$ drop compared to the original levels of the early-1910s. A further drop is observed again during World War II, with a magnitude similar to the drop after the first conflict (10\%), and consequently by the end of the war a total $25 \%$ compared to the original 1910 s levels had occurred.

Regarding the occupational distribution, Figure 7(c) reports the analysis for the share of unskilled workers over the total. Besides the secular increase in the number of skilled workers leaving the country, likely to have in part corresponded with the improvements in the occupational distribution within the U.S. as well as a more positively selected out-migrant flow, the fraction of unskilled migrants appears to have been affected primarily by World War II. The structural break analysis highlights the presence of a break in 1941, corresponding to a decrease in the fraction of unskilled migrants leaving. Indeed, the average share of unskilled migrants dropped by $45 \%$ when comparing the pre- and post-1941 periods.

Figure 7(d) shows the changes in the share of people staying a short time in the U.S. (between 0 and 10 years) versus those who stayed longer. One break is detected in 1921, indicating a 14\% drop in the share of migrants staying for short periods.

Although we can only conjecture on the effective impact of the 1900s events on the characteristics of 
the outflow, referring to the confidence intervals of the point estimates noted above, we could highlight the following patterns.

Out-migrants reacted more strongly to the conflicts and economic turmoil between 1930 and 1950, in comparison with to the surge of restrictive immigration policies. This finding is consistent with the interpretation that the variation in migration patterns can be attributed more to the World Wars and Depression than to immigration policy changes (Hatton and Williamson, 2005). While (Hatton and Williamson, 2005) propose this argument for the inflow of migrants, the present analysis shows that such a hypothesis is also appropriately applied to the outflow and to the characteristics of the out-migrants. In fact, while the wars and the early-1930s affected the sex, age and occupational distribution of the out-migrants, the political changes of the early 1920s primarily had an effect on the length of permanence of the temporary migrants in the U.S.

To summarize we could note three features of the data. First, despite an increase in the outflow over inflow ratio during the 1930s, out-migration declined starting from the early 1920s. Second, the paper uncovers a drop in male out-migration during the late-1920s and 1930s with no changes in the age or skill distribution of the out-migrants. Third, the immigration policy changes of the 1920s appear to be associated with an increase in length of permanence in the U.S. Interestingly, these results are consistent with current analyses such as those by Rendall et al. (2011), who finds that the decline in annual return-migration flows between the U.S. and Mexico during the crisis of 2007-2009 was followed by a drop of male out-migration. Furthermore, the increase in the average duration of a trip is in line with current evidence of the impact of tougher border enforcement concerning Mexican-U.S. migration, which is associated with lower propensity to out-migrate (Thom, 2010, Angelucci, 2012).

\section{The Short-Term Impact of Restrictive Immigration Policies: Any Com- positional Effect on Out-migration?}

The methodology employed in the previous section highlighted the presence of structural changes in average characteristics, albeit only considering the overall behavior over time and controlling for the presence of a trend. Accordingly, in this section I control for country of origin and yearly variation in out-migrant composition, focusing on the introduction of immigration quotas only. This interest in immigration policy is based on two reasons. First, immigration restrictions are of immediate policy relevance and are often discussed in the political arena. Second, available data limits the scope of such analysis to the events up until 1932, given that the INS Annual Reports during the later periods did not consistently provide information on relevant nationalities.

The Congress passed the Literacy Act in 1917, which barred all immigrants who were illiterate. This first attempt to restrict immigration was followed in 1921 by the Emergency Quota Law, which formally ended the era of free immigration to the U.S. The law was enacted on May 19, 1921, and became effective on June 3 of that year. Under the Act of 1921, each nationality was restricted to 3\% of the total resident population of that nationality in 1910, although immigrants from Canada, Mexico, Cuba and South America were exempt from the quota. However, more than 10,000 people entered the U.S. in excess of that month's quota in June 1921 (Annual Report of the Commissioner General of Immigration to the Secretary of Labor 
, 1922, p.18). Given that the cost of expulsion was borne by shipping companies, restrictions started to be enacted at the point of departure. The Immigration Act of 1924 permanently changed the immigration system up until 1965, with the quota for any nationality set at $2 \%$ of its foreign-born population in 1890 . Thereafter, the National Origin Act of 1927 imposed an overall immigration quota of 150,000 people, with the proportion by nationality based on its representation in the 1920 Census. This further adjustment was only implemented in 1929. The immigration restrictions have been associated with a dramatic reduction in immigration.

To study the effect of quotas on the composition of migrant outflow, I collect information on age, occupation and sex distribution by "race or people", relating it to the quota imposed on the comparable nationalities. The dataset has a total of 225 nationality-year cells, with the "race or people" category approximating the information by country of birth, unavailable in the reports. I associate each race to the likely country of birth. I then check the percentage of in-coming migrants who reported the associated country of birth as their country of residence prior to migration. The first two columns of Table 5 show the "races or people", the associated country of birth and the percentage of in-migrants indicating such country as the place of residence prior migration. For example, $83 \%$ of incoming migrants in 1920 categorized as being Greek reported that their residence was Greece. Only nationalities that were likely to correspond to a birthplace in 1924, and for which information on the quota allotted was available, were retained in the analysis, namely Finnish (Finland), French (France), Italian (North/South Italy), Portuguese (Portugal), Rumanian (Romania), Russian (Russia), Scandinavian (Denmark, Sweden, Norway), English (Great Britain and Ireland). Table 5 also shows the quota limits for 1921-1932 and the immigration flow in 1920 for the nationalities of interest. The tightness of the quota on migrant flows widely varied by nationality. This variation is used to correlate the composition of the migrant outflow with a measure of the tightness of the immigration restrictions. I construct an indicator that equals one if the percentage change between pre-quota inflows in 1920 and the quota limit is above the median change. ${ }^{11}$

Table 6 shows the average characteristics of the outflow of migrants in the full sample during 19081932, and by the aforementioned measure of tightness. As found earlier, out-migrants are primarily males, of prime age, and engaged in unskilled occupations. ${ }^{12}$ More than half of the out-migrants stayed in the U.S. for less than 5 years, while more than $80 \%$ of migrants have stayed for a maximum of 10 years. Such characteristics are even more accentuated in the subsample whose flows were more strongly restricted.

However, to determine whether there is any systematic relationship between changes in the composition and immigration legislation, I estimate the panel (fixed effects) regression below. Let $S_{i t}^{c}$ indicate the share of out-migrants of nationality $i$ and characteristic $c$ at time $t$. Let HighQuota $a_{i c t}$ be an indicator of whether the change in flow was above the median change. Accordingly, I estimate:

$$
S_{i t}^{c}=c_{i}+\eta_{t}+\beta_{1} \text { After1924 }_{t}+\beta_{2} \text { HighQuota }_{i t}+\beta_{3} \text { After1924 }_{t} * \operatorname{HighQuota}_{i t}+\varepsilon_{i t}^{c},
$$

\footnotetext{
${ }^{11}$ Here, I assume that the immigration level of 1921 represents the actual supply of migrants that the U.S. would have had, had there been no quotas in the later periods in the five years following the law change. Although there is no doubt that in the long run emigration from Europe would have experienced a backslash even in the absence of immigration restrictions, during the 1920-1930, European migrants moved more within Europe, probably adapting to second-best options(Hatton and Williamson, 2005).

${ }^{12}$ Skilled occupations are defined as professionals, craftsmen and operatives; while unskilled occupations are defined as laborers, servants, and occupations in agriculture
} 
where $c_{i}$ are nationality-specific time invariant traits, $\eta_{t}$ represents various time controls, After1924 is a dummy for the years that following the full implementation of the quota system, and HighQuota ${ }_{i t}$ was defined above.

Time variables are introduced to control for secular trends and cyclical variation in out-migration rates, while nationality-fixed-effects capture persistent traits that may drive differences in out-migration behavior across nationalities. Separating the effects before and after the implementation of the quota system will indicate whether there was a discrete shift in the composition of the flows following the full implementation of the immigration policies. Furthermore, the indicator for quota tightness differentiates between any systematic constant difference in out-migration patterns between nationalities who faced strong restrictions and those who did not. Restrictions specifically targeted the new immigrants from Southern Europe, who did not exhibit similar outcomes to the other immigrants, as explained in Section 2, and hence we cannot presume the former as similar to the latter. The coefficient of most interest is $\beta_{3}$. After having controlled for nationality differences in pre-quota patterns, for nationality-specific out-migration characteristics, and quota variation over time, this interaction term measures the differential impact of quota tightness on the out-migrant composition. ${ }^{13}$

Table 7 reports the main results, with two sets of regressions are run. In the first, $\eta_{t}$ are time-fixed effects capturing year-to-year changes in migrant outflow that that are common across the U.S. Such adjustments reflect both changes in policy and changes in the pushing factors that might have increased overall outmigration. Results from these regressions are reported in the first panel. In the second set of regressions, $\eta_{t}$ corresponds with a linear time trend and nationality-specific time trends, and it is introduced for two reasons: first, to control for nationality-specific time trends, which could correspond to secular changes at origin; and second, as an attempt to control for nationality-specific measurement error. Although this specification still imposes linearity in the error, this second set of regression could better capture time and nationality-varying mistakes in recording outflows. While some variation exists in the results, particularly regarding the average characteristics after 1924, the results on the differential impact of quota tightness are remarkably stable.

The composition of the out-migration flow changed substantially following the imposition of the quota restrictions. After controlling for yearly variation, on average out-migration entered a process of feminization after 1924, with a $6.5 \%$ decrease in the share of male out-migrants. On average, the occupational distribution did not change after 1924, while there is a shift in the age distribution from its middle (outmigrants aged 14-44) towards its extremes, with a 9\% increase in the share of out-migrants aged 45 and older. Finally, there is an average increase in the length of permanence in the U.S. for all the nationalities, and a drop in the share of out-migrants staying 5 to 10 years, followed by an increase in out-migrants staying 10-15 years. Nationalities subject to tighter quotas after 1920 do not exhibit the same out-migration patterns as the other nationalities. In fact, such out-migrants are less likely to be female, more likely to be unskilled, and on average characterized by shorter stays in the U.S. Interestingly, the differential impact of quota restrictions between nationalities subject to tighter quotas compared to the others is not associated with statistically significant changes in the sex, occupational and age distribution of the migrants, but is rather associated with a significant $25 \%$ reduction in the share of out-migrants whose had stayed less than

\footnotetext{
${ }^{13}$ I do not make any claim here on the causal impact of quotas on migrant outflow.
} 
5 years in the U.S., towards increases in the share of migrants staying 5-10 and 10-15 years. These results are also stable when controlling for nationality-specific time trends, after dropping Russians and using a continuous indicator for the change in following immigration quotas. ${ }^{14}$

The use of nationality-specific linear trends introduces greater variability in the analysis, particularly regarding the the average share composition after 1924. In fact, it appears that there was a slight decrease in the percentage of outgoing female, unskilled, and older migrants after the quota policies. We also assist to a larger concentration of migrants leaving within 5 years of stay in the U.S. Interestingly, the same patterns highlighted in the first panel are also present here for the differences between high and low quota migrants, and the differential changes in the shares between these two categories. As before, while tighter quotas did not affect the demographic and occupational characteristics of the out-migrants, they impacted the permanence decisions of constrained nationalities, reducing short stays in favor of longer trips.

In conclusion, there appears to be consistent evidence across the two specifications that immigration restrictions might have raised the cost of each individual trip, hence reducing out-migration. Both panels of Table 7 show an overall change in out-migrant characteristics after 1924 (albeit with less clear directions), and an overall increase in the time spent in the origin country for nationalities subject to greater limitations, namely Southern European migrants. These results are consistent with the breakpoint analysis of Section 4, and are in line with current evidence of the impact of tougher border enforcement on Mexican-U.S. migration.

\section{Conclusions}

Using direct evidence on out-migrant characteristics, this paper explored questions concerning the outflow of migrants from the U.S. between 1908 and 1957, in order to understand whether (borrowing from Lubotsky (2007)) out-migrants are "chutes or ladders," and also whether these flows experienced substantial compositional changes over time.

Despite few differences found in terms of the sex and age structure, the analysis showed that outmigrants were much more likely to engage in unskilled jobs during the first three decades of the century, even after controlling for occupational mobility in the U.S. However, in the 1940s and the 1950s, out-migrants increasingly held more skilled jobs when compared with new arrivals and in-migrants, who had spent a similar amount of time in the U.S.

These results are interesting for two reasons. First, they corroborate the findings obtained by other studies using different methodologies and covering different time periods (e.g. Van Hook et al., 2006, Lubotsky, 2007, Abramitzky et al., 2011). This suggests that even given the presence of different limitations across data methods, all the evidence points towards negative selection in out-migration and varying out-migration rates by demographics. Indeed, this negative selection casts some doubts on the view that migration to the U.S. was characterized by people willing and able to 'Americanize'. Second, the results provide an idea of the out-migrant selection process over time, pointing to increasing quality of the outmigrants. This is of particular value given the scant availability of data on out-migration over several decades. Initially,

\footnotetext{
${ }^{14}$ Results available upon request.
} 
out-migrants were mostly laborers, while over time, the majority eventually engaged in professional, commercial or industrial activities. The increasing positive selection of the outflow is expectable against the backdrop in immigration quality during the 20th century (Hatton and Williamson, 2004) and in line with theoretical predictions (Borjas and Bratsberg, 1996).

I subsequently tested whether these characteristics were impacted by the economic and political events of the time period analyzed, particularly, looking for structural breaks in the average share of males, unskilled out-migrants, individuals aged 14-44 years, and individuals who stayed for a maximum of 10 years. While I found substantial structural changes during the war periods and the Depression, these shares seemed to have only partially reacted to the immigration laws introduced in the 1920s.

This result is also consistently found in Section 5, where the paper further explored the link between such laws and shifts in out-migrant characteristics now conditioning of nationality-specific experiences. Even after controlling for nationality-specific linear trends that might capture variation in measurement error over time, the results showed that restrictions impacted trip duration, shifting the distribution towards longer stays for nationalities subject to tight quotas. Therefore, the analysis highlighted that migration policies might not only impact the flow of incoming individuals, but also the characteristics of the temporary migrants. Controlling for yearly time effects, the U.S. kept unskilled and younger individuals who settled for longer periods within its borders after the quotas of 1924, while the sending regions received older, skilled individuals, with more than 10 years of experience in America. Accordingly, out-migration seems to have redistributed productive sources from the host to the home regions. 
A Tables 
Table 1: Out-Migration Rate Estimates for 19101920, Bandiera et al. (2010) and INS reports, by Characteristics

Bandiera et al. (2010) INS reports

Table 4, Column 6

Overall rate

0.975

0.347

Male

0.960

0.433

Female

0.992

0.189

Age $<14$

1.137

0.127

Age 15+

0.780

0.382

Germany

1.217

0.206

Great Britain

0.951

0.258

Greece

0.852

2.240

Ireland

0.939

0.179

Italy

0.838

1.778

Russia

0.973

1.080

Spain

0.895

0.496

Column 2 reports the out-migration rate as estimated in Bandiera et al. (2012) for the decade 1910-1920.

Column 3 reports the out-migration rate calculated from the INS Annual Reports. Total inflows and outflows of migrants between 1910 and 1920 (included) by characteristics and by race or people have been used.

Note: the INS reports do not provide information by nationality at birth. "Race or people" has been used instead. A correspondence between "race or people" and "country of residence prior migration" (which might approximate birthplace) is reported in Table 5. 
Table 2: Average Sex, Age, and Occupational Distribution for Incoming and Outgoing Migrants, 1908-1924

\begin{tabular}{lcc}
\hline & Inflow & Outflow \\
\hline $\begin{array}{l}\text { Sex } \\
\quad \text { Male }\end{array}$ & 0.502 & 0.665 \\
& & \\
\hline Age & & \\
$0-14$ & 0.169 & 0.072 \\
$15-44$ & 0.699 & 0.679 \\
$45+$ & 0.132 & 0.245 \\
\hline Occupation & & \\
$\quad$ Highly skilled & 0.058 & 0.059 \\
Skilled & 0.213 & 0.177 \\
Farmers & 0.081 & 0.038 \\
Unskilled & 0.165 & 0.358 \\
Other/Unknown & 0.485 & 0.374 \\
\hline \multicolumn{2}{l}{ Source; Authors }
\end{tabular}

Source: Author's elaborations.

Notes: Highly Skilled = professionals; Skilled $=$ commercial and skilled artisans; Unskilled = laborers. 
Table 3: Sex, Age, and Occupational Distribution for the Immigrant Stock and Outgoing Migrants

\begin{tabular}{|c|c|c|c|c|c|}
\hline & 1910 & 1920 & 1930 & 1940 & 1950 \\
\hline \multicolumn{6}{|l|}{ Outflow } \\
\hline \multicolumn{6}{|l|}{ Sex } \\
\hline Males & 0.765 & 0.825 & 0.643 & 0.643 & 0.519 \\
\hline \multicolumn{6}{|l|}{ Age } \\
\hline $0-14$ & 0.068 & 0.037 & 0.069 & 0.046 & 0.085 \\
\hline $15-44$ & 0.827 & 0.705 & 0.675 & 0.632 & 0.564 \\
\hline $45+$ & 0.105 & 0.257 & 0.256 & 0.321 & 0.351 \\
\hline \multicolumn{6}{|l|}{ Occupation } \\
\hline Highly Skilled & 0.024 & 0.043 & 0.055 & 0.132 & 0.225 \\
\hline Skilled & 0.198 & 0.443 & 0.589 & 0.302 & 0.549 \\
\hline Farmers & 0.048 & 0.227 & 0.037 & 0.086 & 0.084 \\
\hline Unskilled & 0.729 & 0.287 & 0.319 & 0.481 & 0.142 \\
\hline \multicolumn{6}{|l|}{ Immigrant Stock } \\
\hline \multicolumn{6}{|l|}{ Sex } \\
\hline Male & 0.6048 & 0.5582 & 0.5171 & 0.5259 & 0.5115 \\
\hline \multicolumn{6}{|l|}{ Age } \\
\hline $0-14$ & 0.124 & 0.124 & 0.114 & 0.038 & 0.057 \\
\hline $15-44$ & 0.809 & 0.788 & 0.781 & 0.360 & 0.292 \\
\hline $45+$ & 0.067 & 0.088 & 0.105 & 0.602 & 0.651 \\
\hline \multicolumn{6}{|l|}{ Occupation } \\
\hline Highly Skilled & 0.015 & 0.020 & 0.034 & 0.043 & 0.054 \\
\hline Skilled & 0.646 & 0.660 & 0.716 & 0.726 & 0.774 \\
\hline Farmers & 0.098 & 0.101 & 0.064 & 0.104 & 0.076 \\
\hline Unskilled & 0.241 & 0.219 & 0.186 & 0.127 & 0.096 \\
\hline
\end{tabular}

Source: Author's elaborations from INS Annual Reports.

Notes: Highly Skilled = professionals; Skilled = commercial and skilled artisans; Unskilled $=$ laborers. 
Table 4: Timing and Size of Structural Breaks in Out-Migrant Composition, 1908-1957

\begin{tabular}{lccc}
\hline & Break Point Estimate & Confidence Interval & Associated Change in Average Share \\
\hline Males & 1927 & {$[1926,1939]$} & $-0.198^{* * *}$ \\
& 1917 & {$[1916,1923]$} & $(0.018)$ \\
\hline Age 14-44 & 1944 & {$[1942,1945]$} & $-0.153^{* * *}$ \\
& & & $(0.020)$ \\
& 1941 & {$[1940,1943]$} & $-0.255^{* * *}$ \\
& & & $(0.022)$ \\
\hline Unskilled & 1920 & {$[1918,1921]$} & $-0.454^{* * *}$ \\
& & & $(0.032)$ \\
\hline Length 0-10 Years & & $-0.143^{* * *}$ \\
& & $(0.014)$ \\
\hline
\end{tabular}

Significance levels: ${ }^{*}: 10 \%,{ }^{* *}: 5 \%,{ }^{* * *}: 1 \%$

Estimates of breakpoints and confidence intervals are based on Bai and Perron (2003).

The associated change in the average share of males, individuals aged 14-44, unskilled workers (farmers+laborers) and length of permanence below 10 years have been obtained as the difference in the average across the partitions determined by the breakpoint test.

Sources: INS Annual Reports, 1908-1957. Length of residence in the U.S. is restricted to 1908-1932.

Table 5: Nationality Used and Relative Quota Allocation, 1921-1932

\begin{tabular}{llcccc}
\hline Race or People & Country Assigned & Immigration Act 1921 & Immigration Act 1924 & Quotas Effective 1930 & Inflow 1920 \\
\hline Finnish & Finland - 86\% & 3921 & 471 & 569 & 4233 \\
French & France - 82\% & 5729 & 3954 & 3086 & 24122 \\
Greek & Greece - 83\% & 3894 & 100 & 307 & 31828 \\
Italian & Italy - 98\% & 42057 & 3845 & 5802 & 222496 \\
Portuguese & Portugal - 99\% & 2465 & 503 & 440 & 18856 \\
Russian & Russia - 48\% & 24405 & 2248 & 2784 & 2887 \\
Scandinavian & Norway, Denmark, Sweden - 97\% & 37863 & 18803 & 6872 & 25812 \\
Spanish & Spain - 97\% & 912 & 131 & 252 & 27448 \\
English/Irish & UK and Ireland - 98\% & 77342 & 62574 & 83574 & 120080 \\
\hline
\end{tabular}

The first column reports the "race or people" used in the analysis. The second column reports the primary country of provenience in 1920 of the people in analysis and in which percentage. Column 2,3, and 4 reports the quota allotted to each nationality under the various acts and column 5 reports the inflow before the quotas were enacted. 
Table 6: Average Characteristics, Full sample and High/Low Quota Year-Nationality Pairs, 1908-1932

\begin{tabular}{lrrr}
\hline & Overall & High Quota & Low Quota \\
\hline Male & 0.743 & 0.835 & 0.721 \\
Unskilled & $(0.141)$ & $(0.049)$ & $(0.147)$ \\
& 0.749 & 0.892 & 0.714 \\
Age 14-44 & $(0.156)$ & $(0.055)$ & $(0.152)$ \\
& 0.787 & 0.758 & 0.794 \\
Age 45+ & $(0.080)$ & $(0.093)$ & $(0.075)$ \\
& 0.172 & 0.216 & 0.161 \\
Length under 5 & 0.632 & 0.575 & 0.645 \\
& $(0.182)$ & $(0.160)$ & $(0.185)$ \\
Length 5-10 & 0.234 & 0.237 & 0.233 \\
& $(0.136)$ & $(0.102)$ & $(0.143)$ \\
Length 10-15 & 0.078 & 0.112 & 0.070 \\
& $(0.060)$ & $(0.058)$ & $(0.058)$ \\
Length 15-20 & 0.032 & 0.047 & 0.028 \\
& $(0.035)$ & $(0.036)$ & $(0.033)$ \\
Length over 20 & 0.025 & 0.029 & 0.023 \\
& $(0.023)$ & $(0.024)$ & $(0.023)$ \\
N & 225 & 44 & 181 \\
\hline
\end{tabular}

Average characteristics for the 1908-1932 period. Full sample includes: Finnish (Finland), French (France), Italian (North/South Italy), Portuguese (Portugal), Russian (Russia), Scandinavian (Denmark, Norway, Sweden), Spanish (Spain), English (Great Britain and Ireland). 
Table 7: Quota Restrictions and the Composition of Migrant Outflow, 1908-1932

\begin{tabular}{|c|c|c|c|c|c|c|c|c|}
\hline & Females & Unskilled & Age $14-44$ & Age 45+ & Length $0-5$ & Length 5-10 & Length $10-15$ & Length $15-20$ \\
\hline \multirow[t]{2}{*}{ High Quota } & $-0.086^{* * *}$ & $0.100^{* * *}$ & $0.039^{*}$ & $-0.047^{* *}$ & $0.157^{* * *}$ & $-0.075^{* *}$ & $-0.048^{* *}$ & -0.014 \\
\hline & $(0.021)$ & $(0.031)$ & $(0.022)$ & $(0.020)$ & $(0.048)$ & $(0.037)$ & $(0.019)$ & $(0.011)$ \\
\hline \multirow[t]{2}{*}{ After 1924} & $0.065^{* * *}$ & 0.016 & $-0.150^{* * *}$ & $0.094^{* * *}$ & 0.031 & $-0.120^{* * *}$ & $0.066^{* * *}$ & 0.012 \\
\hline & $(0.024)$ & $(0.035)$ & $(0.026)$ & $(0.023)$ & $(0.055)$ & $(0.043)$ & $(0.021)$ & $(0.013)$ \\
\hline \multirow[t]{2}{*}{ High Quota*After1924 } & 0.020 & 0.039 & -0.016 & 0.023 & $-0.250^{* * *}$ & $0.139^{* * *}$ & $0.079^{* * *}$ & 0.013 \\
\hline & $(0.022)$ & $(0.032)$ & $(0.024)$ & $(0.021)$ & $(0.051)$ & $(0.040)$ & $(0.020)$ & $(0.012)$ \\
\hline Time Fixed Effects & Yes & Yes & Yes & Yes & Yes & Yes & Yes & Yes \\
\hline Nationality Effects & Yes & Yes & Yes & Yes & Yes & Yes & Yes & Yes \\
\hline \multirow[t]{2}{*}{ High Quota } & $0.041^{*}$ & 0.037 & 0.025 & $-0.034^{* *}$ & $0.167^{* * *}$ & $-0.193^{* * *}$ & 0.02 & 0.005 \\
\hline & $(0.021)$ & $(0.024)$ & $(0.018)$ & $(0.017)$ & $(0.050)$ & $(0.044)$ & $(0.017)$ & $(0.008)$ \\
\hline \multirow[t]{2}{*}{ After 1924} & $-0.028^{*}$ & $-0.050^{*}$ & $0.029^{*}$ & $-0.025^{*}$ & $0.366^{* * *}$ & $-0.293^{* * *}$ & $-0.060^{* * *}$ & 0.001 \\
\hline & $(0.016)$ & $(0.019)$ & $(0.015)$ & $(0.013)$ & $(0.040)$ & $(0.035)$ & $(0.014)$ & $(0.006)$ \\
\hline \multirow[t]{2}{*}{ High Quota*After1924 } & 0.022 & -0.004 & 0.018 & -0.017 & $-0.242^{* * *}$ & $0.151^{* * *}$ & $0.061^{* * *}$ & 0.011 \\
\hline & $(0.025)$ & $(0.029)$ & $(0.022)$ & $(0.021)$ & $(0.061)$ & $(0.053)$ & $(0.021)$ & $(0.010)$ \\
\hline Linear Trend & Yes & Yes & Yes & Yes & Yes & Yes & Yes & Yes \\
\hline Nationality Effects & Yes & Yes & Yes & Yes & Yes & Yes & Yes & Yes \\
\hline Nationality-specific Trend & Yes & Yes & Yes & Yes & Yes & Yes & Yes & Yes \\
\hline
\end{tabular}

Significance levels: ${ }^{*}: 10 \%,{ }^{* *}: 5 \%,{ }^{* * *}: 1 \%$

Source: Annual Reports, 1908-1932. All regressions are based on 225 year-nationality observations.

Full sample includes: Finnish (Finland), French (France), Italian (North/South Italy), Portuguese (Portugal), Russian (Russia), Scandinavian (Denmark, Norway, Sweden), Spanish (Spain), English (Great Britain and Ireland). 


\section{B Figures}

Figure 1: Inflows and Outflows of Migrants, 1908-1957

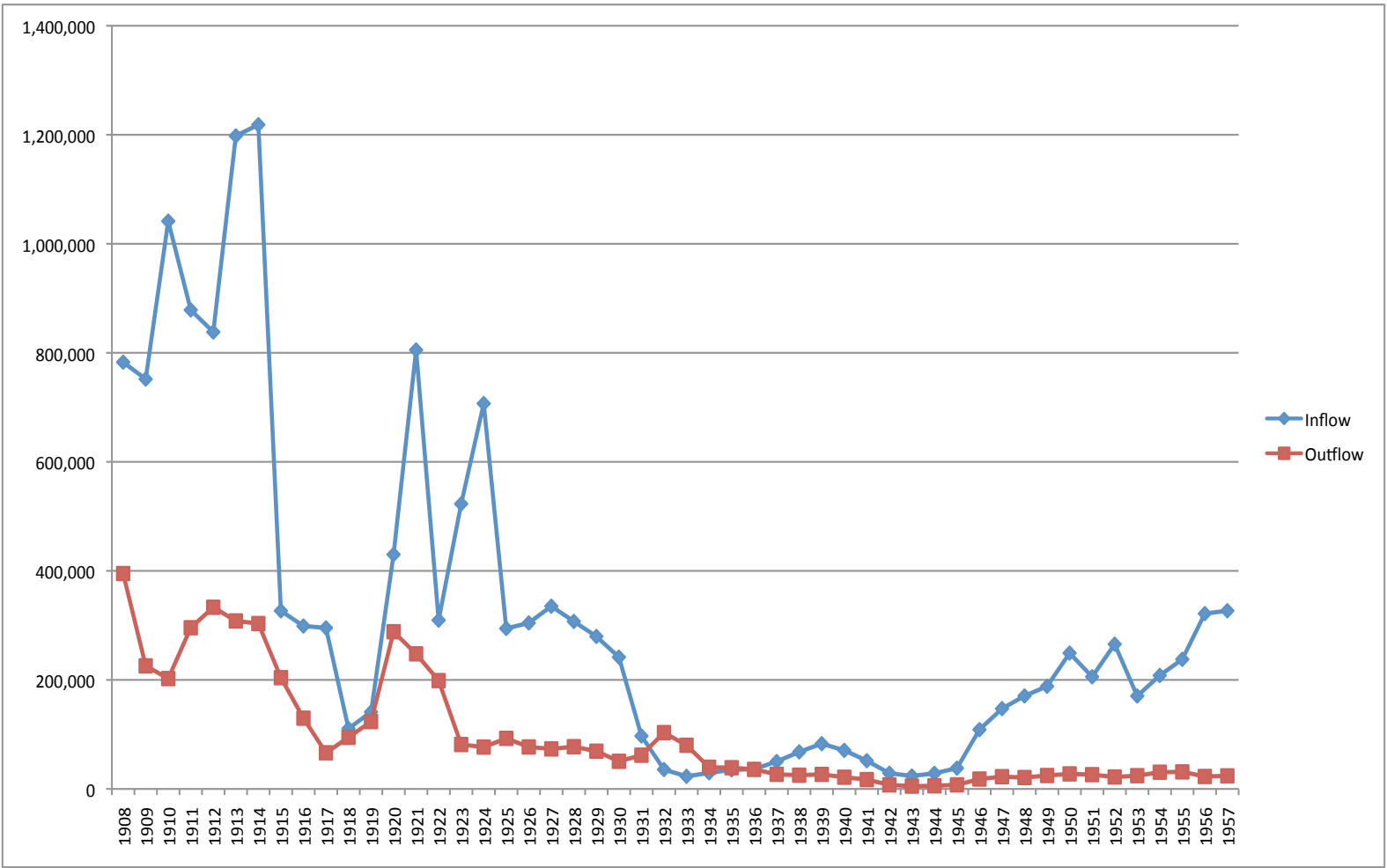

Source: Carter et al. (2006) 
Figure 2: Outflow as a Ratio to Inflow of Migrants, 1908-1957

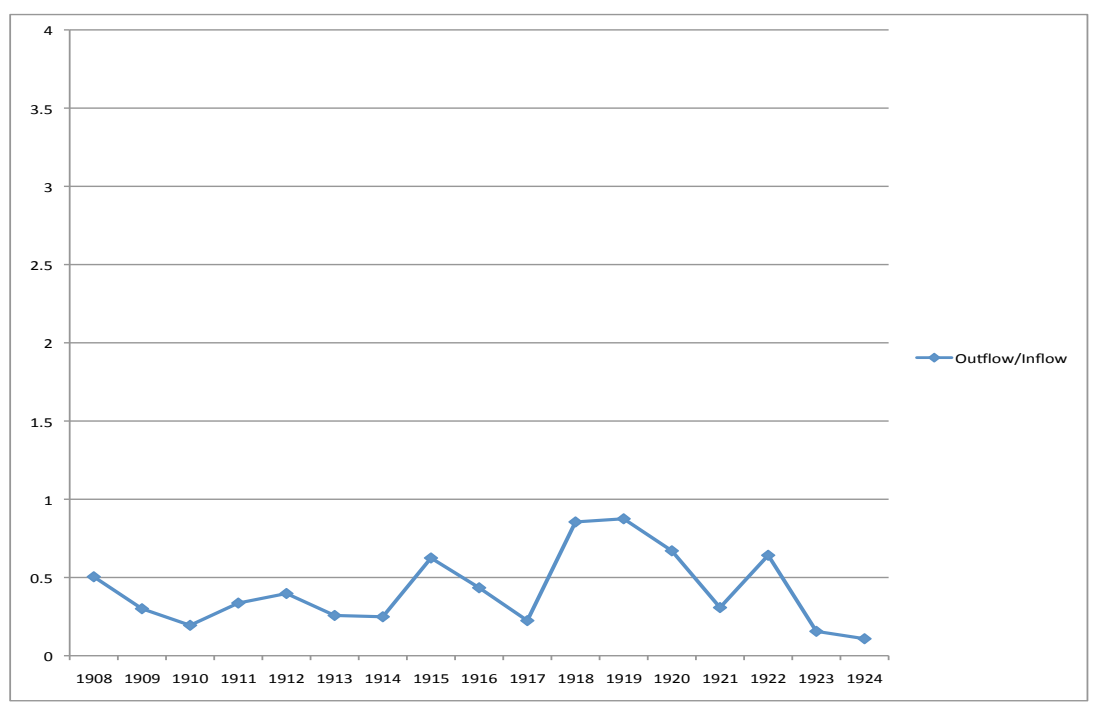

(a) 1908-1924

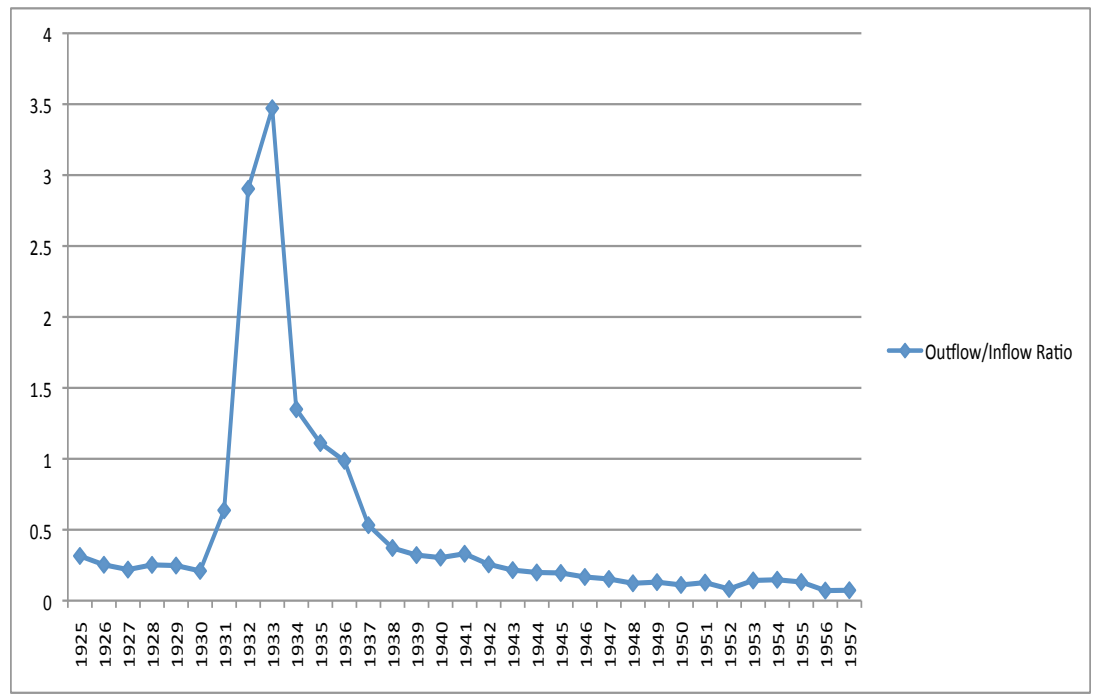

(b) $1925-1957$

Source: Carter et al. (2006) 
Figure 3: Outflow as a Ratio to Inflow of Migrants, by Gender, 1908-1957

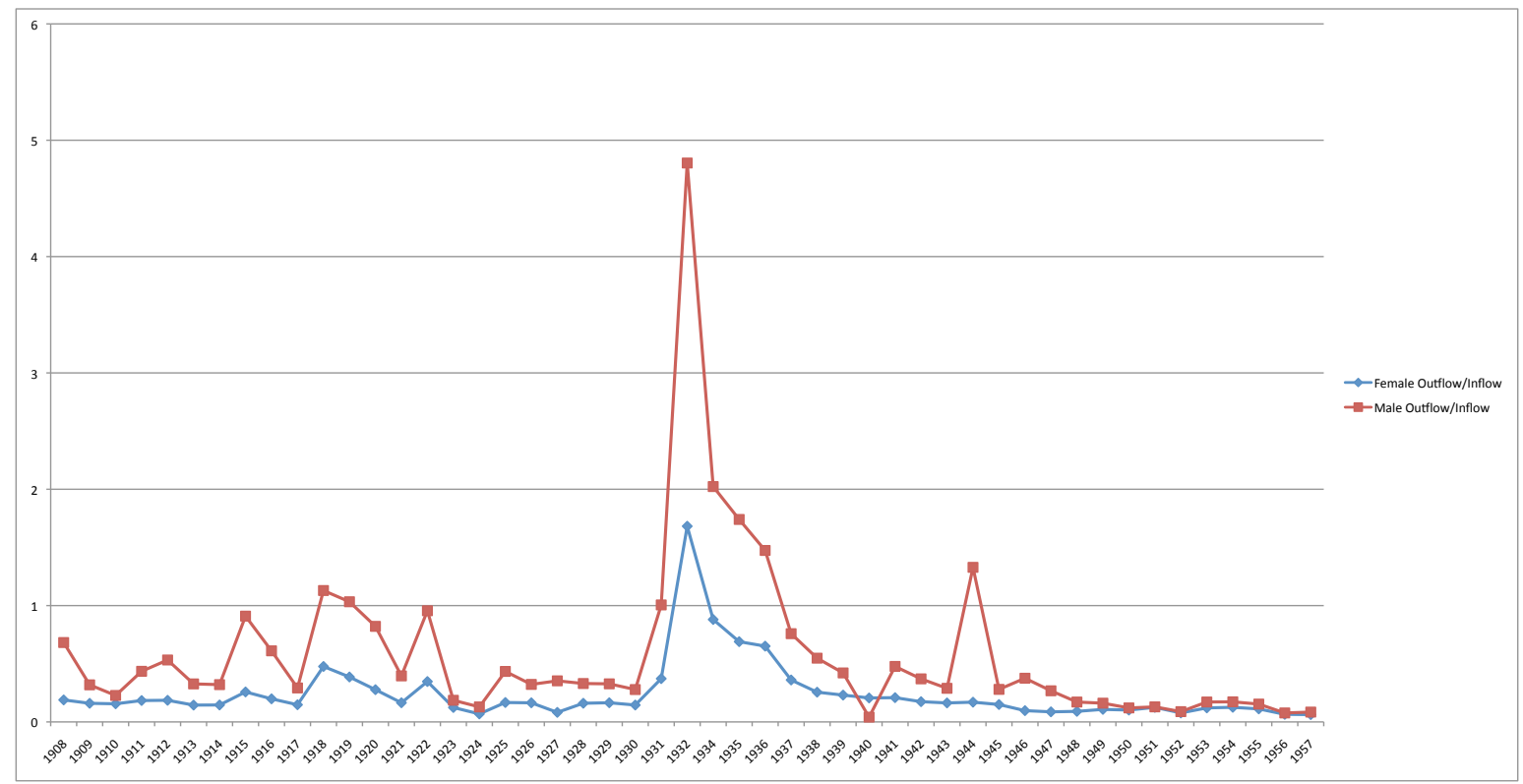

Source: Authors' elaborations from INS Annual Reports. 
Figure 4: Outflow and Inflow of Migrants, by Sex, 1908-1957

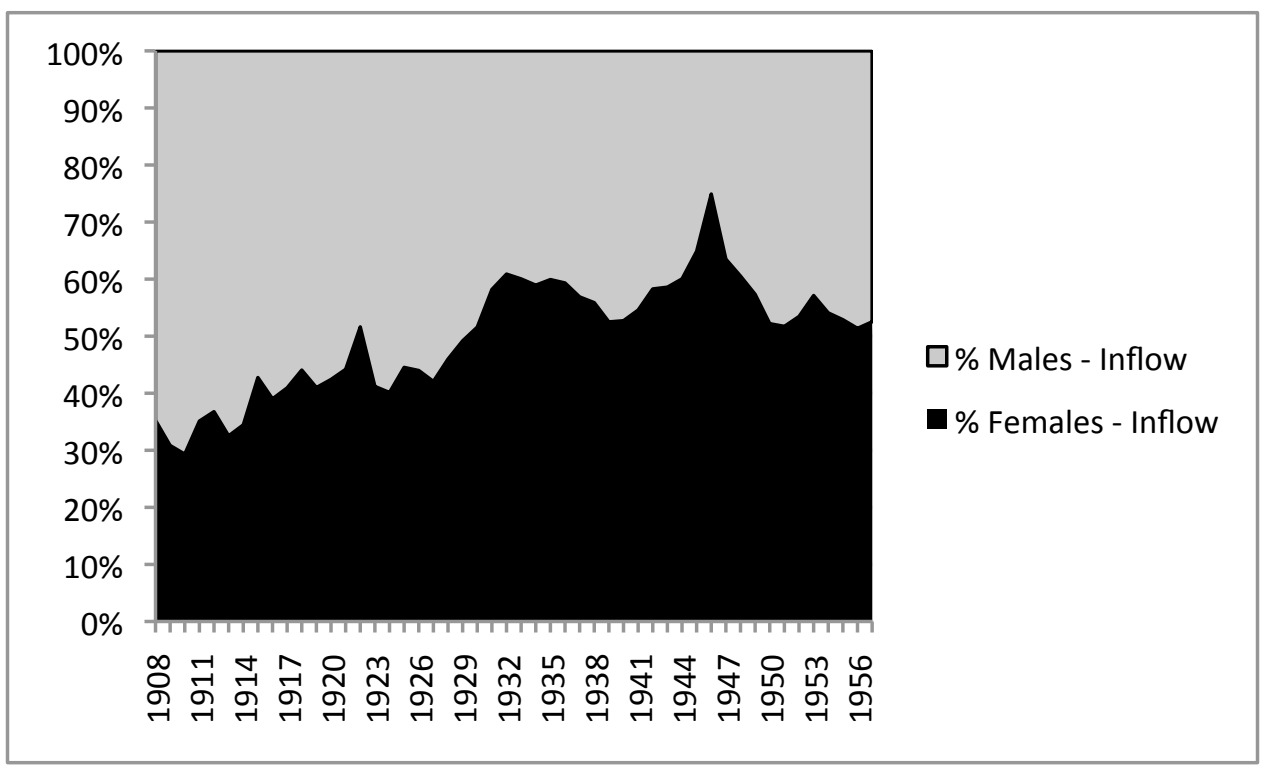

(a) Sex Distribution, Incoming Aliens

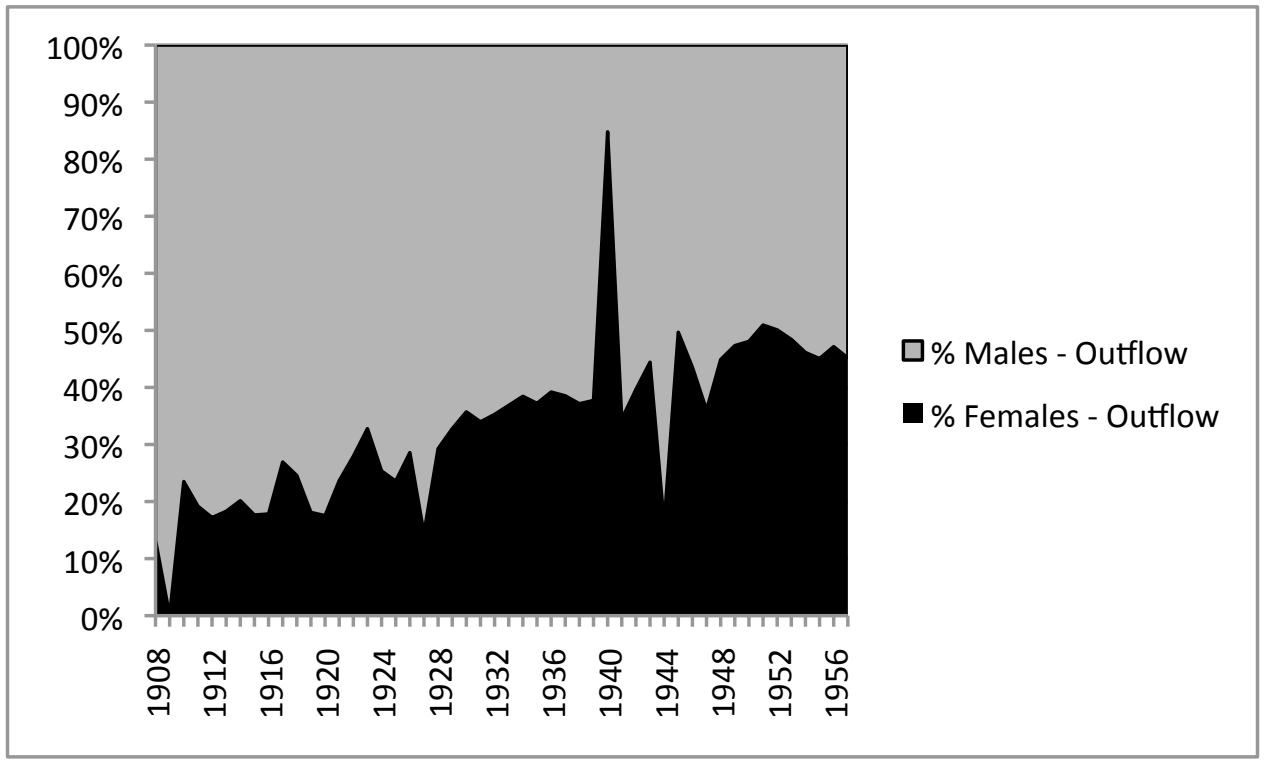

(b) Sex Distribution, Outgoing Aliens

Source: Authors' elaborations from INS Annual Reports. 
Figure 5: Outflow and Inflow of Migrants, by Age, 1908-1957

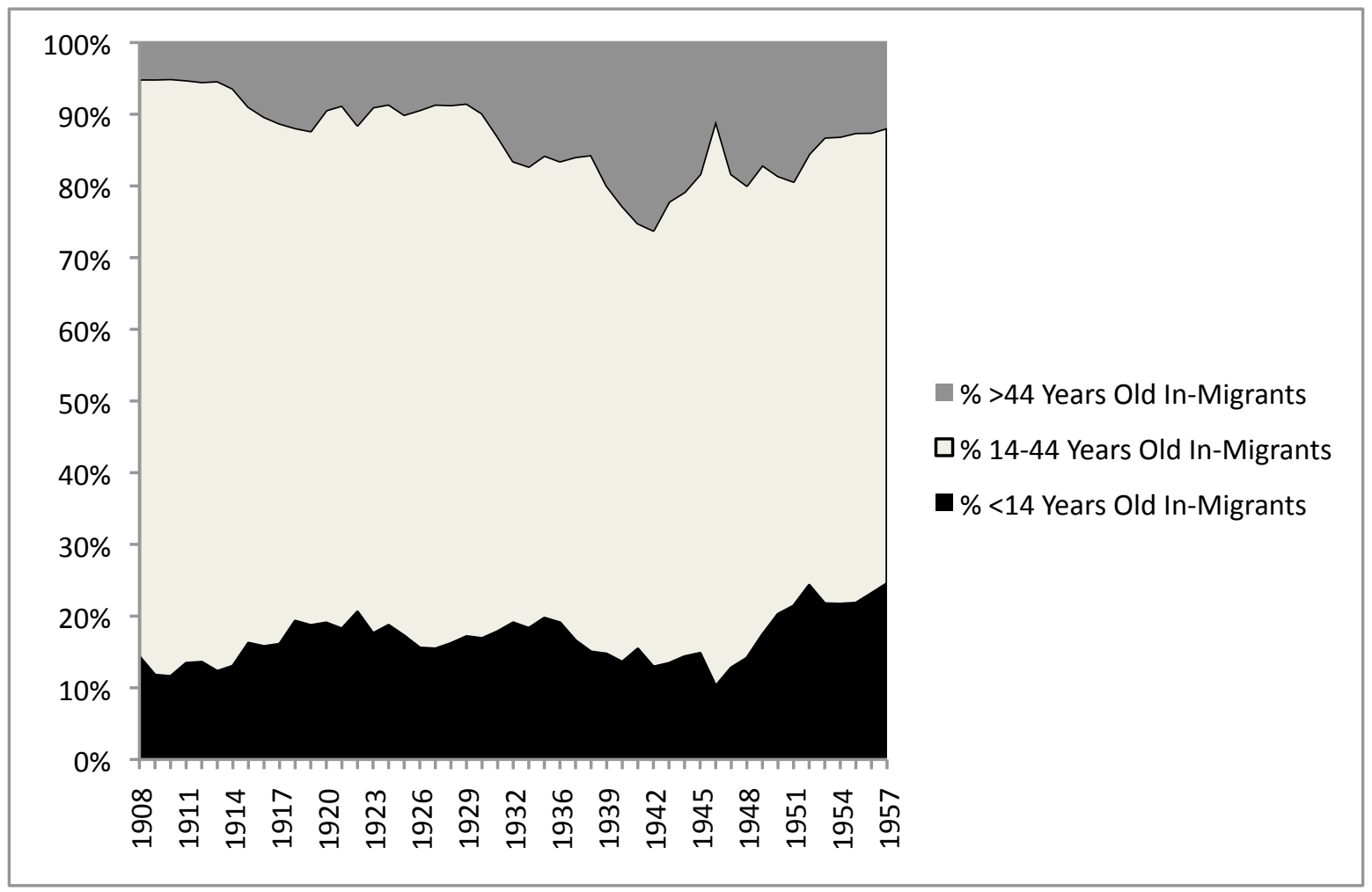

(a) Age Distribution, Incoming Aliens

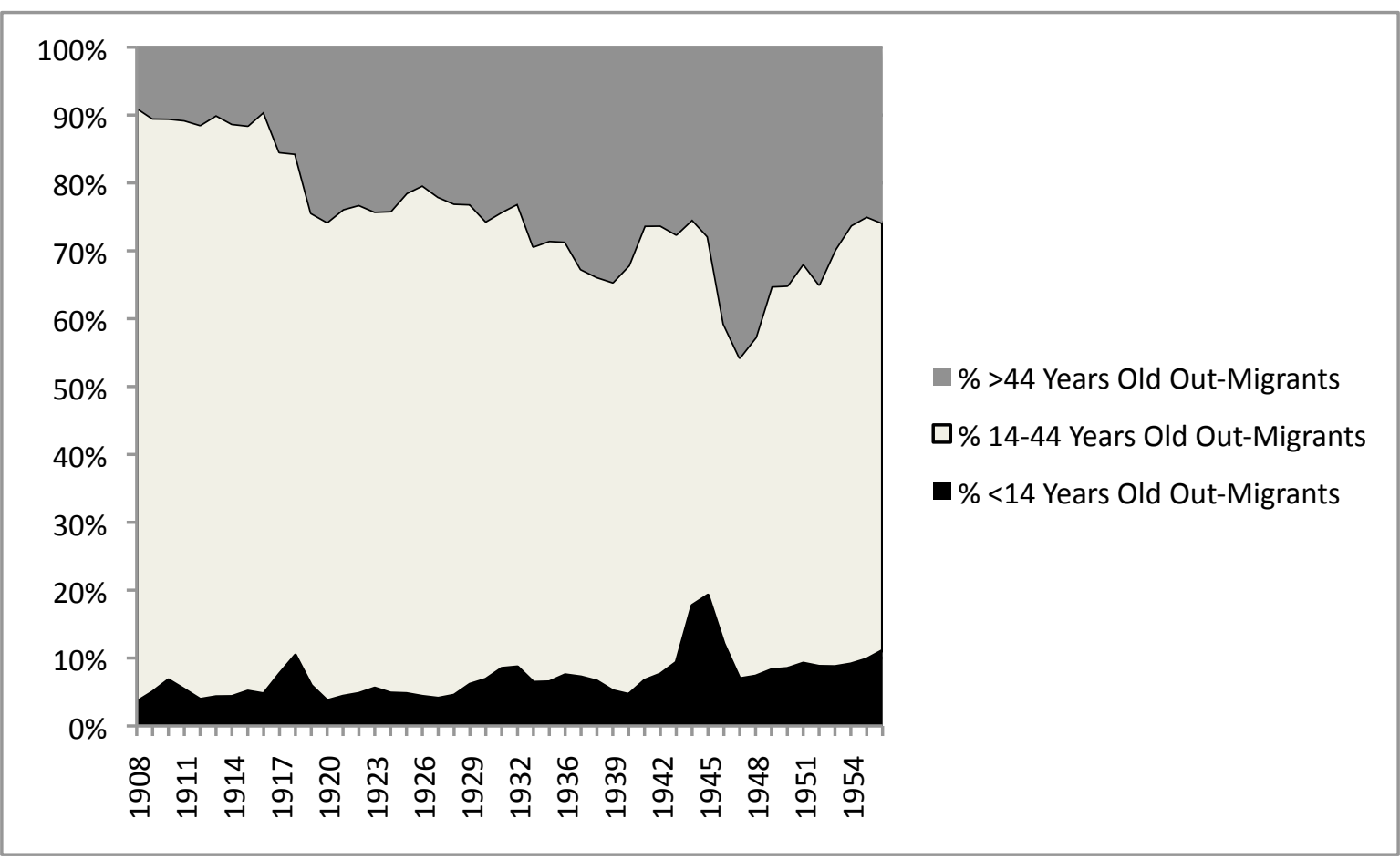

(b) Age Distribution, Outgoing Aliens

Source: Authors' elaborations from INS Annual Reports. 
Figure 6: Occupational Distribution, over Time, 1910-1950 for Italians and Russians

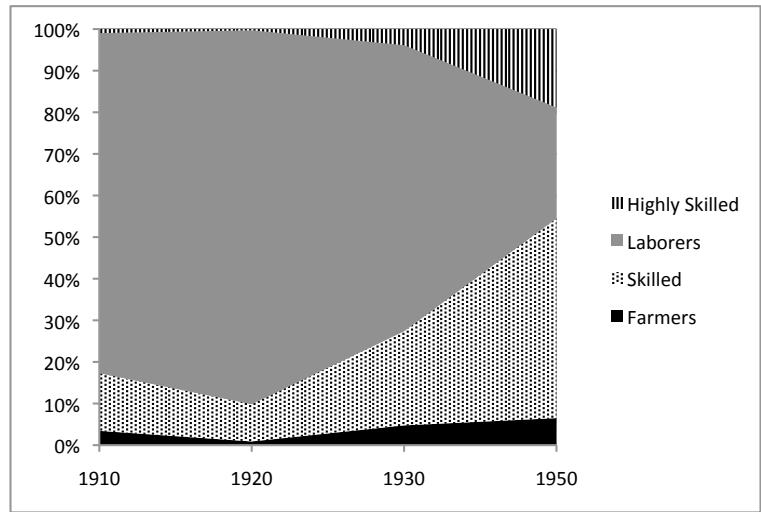

(a) Italian Out-migration Flow

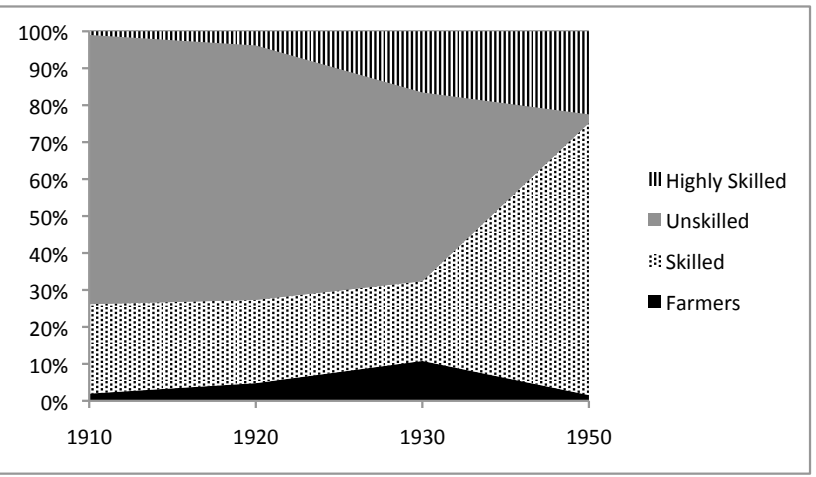

(c) Russian Out-migration Flow

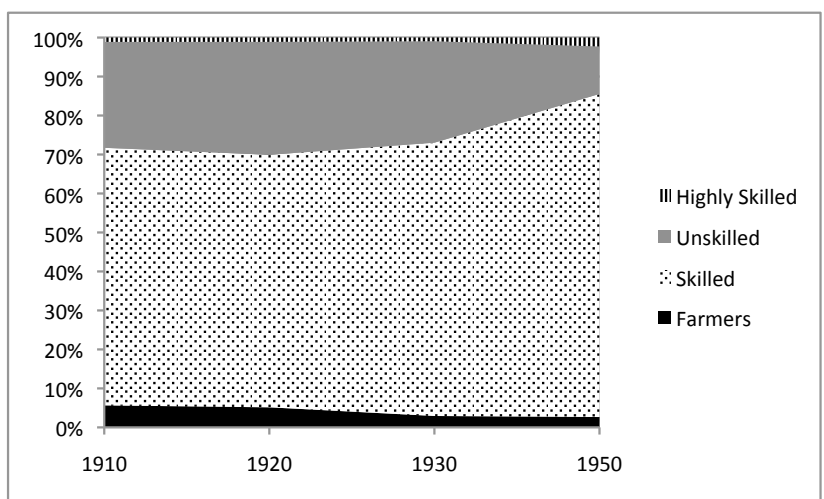

(b) Italian Immigration Stock

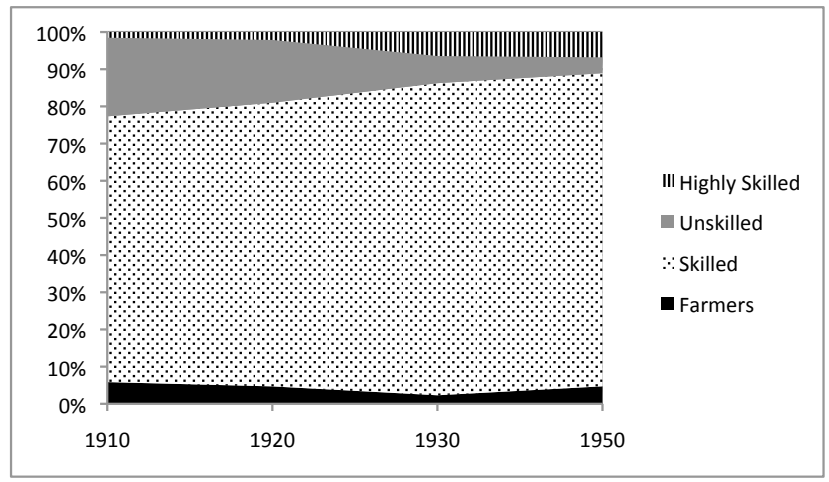

(d) Russian Immigration Stock

Sources: INS Annual Report 1910, 1921, 1930, 1950 and Integrated Public Use Microcensus Data for 1910, 1920, 1930, 1940, 1950. 
Figure 7: Structural Break Analysis for Sex Composition (a),Age (b), Occupation (c), and Length of Stay (d).

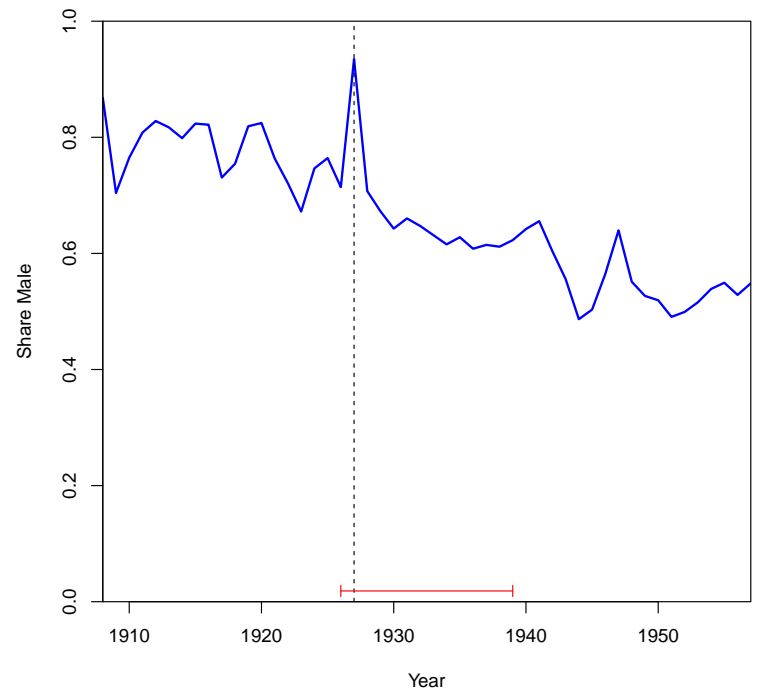

(a) Share of Male Out-migrants

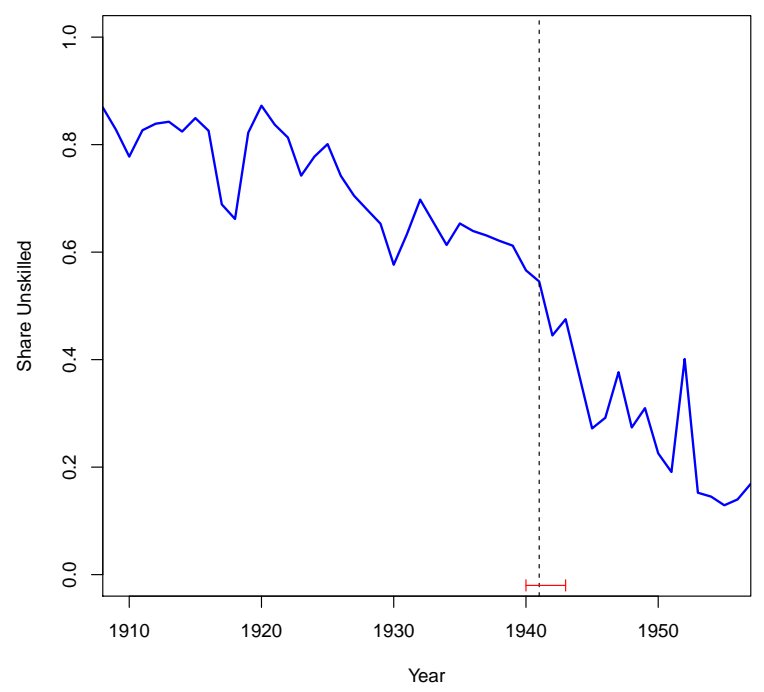

(c) Share of Unskilled Out-migrants

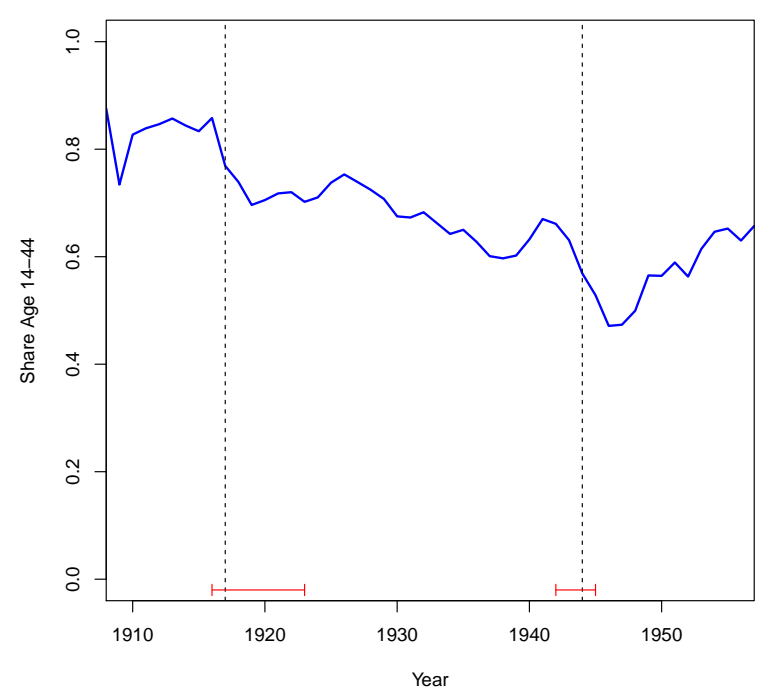

(b) Share of Out-migrants Aged 14-44

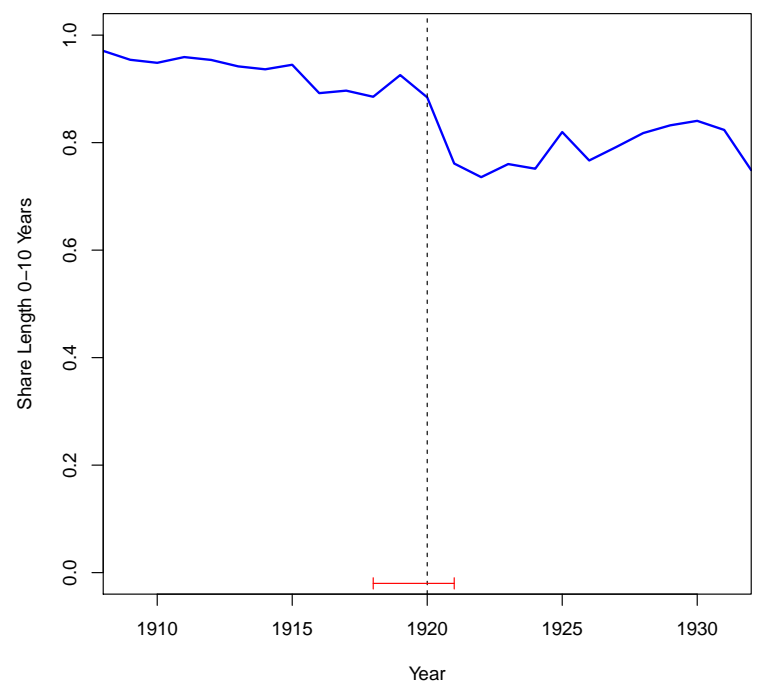

(d) Share of Out-migrants with 0-10 Years in the U.S. 


\section{References}

Abramitzky, Ran, Leah Boustan, and Katherine Eriksson, "A Nation of Immigrants: Assimilation and Economic Outcomes in the Age of Mass Migration," 2011. Draft presented at the 2011 Migration and Development Conference at the Harvard Kennedy School.

Ambrosini, J. William and Giovanni Peri, "The Determinants and the Selection of Mexico-US Migrants," The World Economy, 02 2012, 35 (2), 111-151.

_, Karin Mayr, Giovanni Peri, and Dragos Radu, "The Selection of Migrants and Returnees: Evidence from Romania and Implications,” Working Paper 16912, National Bureau of Economic Research 2011.

Angelucci, Manuela, "U.S. Border Enforcement and the Net Flow of Mexican Illegal Migration," Economic Development and Cultural Change, 2012, 60 (2), 311 - 357.

Axelrod, Bernard, "Historical Studies of Emigration from the United States," International Migration Review, 1972, 6 (1), 32-49.

Bai, J., "Estimation of a Change Point in Multiple Regression Models," Review of Economics and Statistics, 1997, $79(4), 551-563$.

_ and P. Perron, "Estimating and Testing Linear Models with Multiple Structural Changes," Econometrica, 1998, pp. 47-78.

_ and _, "Computation and Analysis of Multiple Structural Change Models," Journal of Applied Econometrics, 2003, $18(1), 1-22$.

Bailey, W. B., “The Bird of Passage,” The American Journal of Sociology, 1912, 18 (3), pp. 391-397.

Bandiera, Oriana, Imran Rasul, and Martina Viarengo, "The Making of Modern America: Migratory Flows in the Age of Mass Migration," forthcoming Journal of Development Economics, 2012, doi: 10.1016/j.jdeveco.2012.11.005.

Barrett, Alan and Philip J. O'Connell, "Is There a Wage Premium for Returning Irish Migrants," IZA Discussion Paper Series, 2000, No. 135.

Biavaschi, Costanza, "The labor demand was downward sloping: Disentangling migrants' inflows and outflows, 1929-1957," Economics Letters, 2013, 118 (3), 531 - 534.

Bloch, Louis, "Occupations of Immigrants Before and After Coming to the United States," Quarterly Publications of the American Statistical Association, 1921, 17 (134), pp. 750-764.

Borjas, George J. and Bernt Bratsberg, "Who Leaves? The Outmigration of the Foreign-Born," The Review of Economics and Statistics, February 1996, 78 (1), 165-176. 
Carter, Susan B., Scott Sigmund Gartner, Michael R. Haines, Alan L. Olmstead, Richard Sutch, Gavin Wright, and Susan B. Carter, Historical Statistics of the United States Millennial Edition Online, New York: Cambridge University Press, 2006.

Co, Catherine Y., Ira N. Gang, and Myeong-Su Yun, "Returns to returning," Journal of Population Economics, 2000, 23, 57-79.

COM, "On circular migration and mobility partnerships between the European Union and third countries," Technical Report, Commission of the European Communities 2007.

Constant, Amelie and Douglas S. Massey, "Self-Selection, Earnings, and Out-Migration: a Longitudinal Study of Immigrants to Germany," Journal of Population Economics, December 2003, 16, 631-653.

Coulon, Augustin De and Matloob Piracha, "Self-Selection and the Performance of Return Migrants: the Source Country Prospective," Journal of Population Economics, 2005, 18, 779-807.

Djajifà, Slobodan and Ross Milbourne, "A General Equilibrium Model of Guest-Worker Migration: the Source Country Perspective," Journal of International Economics, 1988, 25 (3-4), 335-351.

Dustmann, C. and Y. Weiss, "Return migration: theory and empirical evidence from the UK," British Journal of Industrial Relations, 2007, 45 (2), 236-256.

Ferrie, Joseph P., Yankeys Now: Immigrants in the Antebellum U.S. 1840-1860, Oxford University Press, 1999.

_, "The End of American Exceptionalism? Mobility in the U.S. Since 1850," October 2004. Working Paper.

GCIM, "Migration in an Interconnected World: New Directions for Action. Geneva, Report of the Global Commission on International Migration.," Report, Global Commission on International Migration 2005.

Gemery, Henry A., "Immigrants and Emigrants: International Migration and the U.S. labor market in the Great Depression," in Timothy J. Hatton and Jeffrey G. Williamson, eds., Migration and the International Labor Market 1850-1939, Routledge, 1994.

Hatton, Timothy J. and Jeffrey G. Williamson, "International Migration in the Long Run: Positive Selection, Negative Selection and Policy,” Discussion Paper 1304, Institute for the Study of Labor 2004.

_ and _, Global Migraton and the World Economy: Two Centuries of Policy and Performance, The MIT Press, 2005.

Hook, Jennifer Van, Weiwei Zhang, Frank D. Bean, and Jeffrey S. Passel, "Foreign-born emigration: A new approach and estimates based on matched CPS files," Demography, 2006, 43 (2), 361-382.

Hu, Wei-Yin, "Immigrant earnings assimilation: estimates from Longitudinal data," The American Economic Review, 2000, 90 (2), 368-372. 
Hutchinson, E. P., "Notes on Immigration Statistics of the United States," Journal of the American Statistical Association, 1958, 53 (284), 963-1025.

IOM, "IOM Strategy Document, Annex, Resolutions adopted by the Council at its Ninety-Third (special) Session, MC/2218,” Technical Report, International Organization for Migration 2007.

Jasso, Guillermina and Mark R. Rosenzweig, "Estimating the Emigration Rates of Legal Immigrants Using Administrative and Survey Data: The 1971 Cohort of Immigrants to the United States," Demography, 1982, 19 (3), 279-290.

Jerome, Harry, Migration and Business Cycles, NBER, 1926.

Kraly, Ellen Percy, "Emigration: Implications for US immigration policy research," Migration Between Mexico and the United States: Binational Study, 1998, 2, 587-618.

Kuznets, Simon and Ernest Rubin, Immigration and the Foreign Born, NBER, 1954.

Lacuesta, Aitor, "A Revision of the Self-Selection of Migrants Using Returning Migrants Earnings," Annals of Economics and Statistics, 2010, 97/98, 235-259.

Lindstrom, D. P. and D. S. Massey, "Selective Emigration, Cohort Quality, and Models of Immigrant Assimilation,” Social Science Research, 1994, 23 (4), 315 - 349.

Lubotsky, Darren, "Chutes or Ladders? A Longitudinal Analysis of Immigrant Earnings," Journal of Political Economy, 2007, 115 (5), 820-867.

Massey, Douglas S., "Understanding Mexican Migration to the United States," The American Journal of Sociology, 1987, 92 (6), pp. 1372-1403.

McKenzie, David and Hillel Rapoport, "Self-selection Patterns in Mexico-U.S. Migration: the Role of Migration Networks," The Review of Economics and Statistics, 2010, 92 (4), 811-821.

Patel, Krishna and Francis Vella, "Immigrant Networks and Their Implications for Occupational Choice and Wages," IZA Discussion Paper Series, December 2007, (3217).

Reagan, Patricia B. and Randall J. Olsen, "You Can Go Home Again: Evidence from Longitudinal Data," Demography, 2000, 37 (3), pp. 339-350.

Reinhold, Steffen and Kevin Thom, "Migration Experience and Earnings in the Mexican Labor Market," 2011. Working Paper.

Rendall, Michael S., Peter Brownell, and Sarah Kups, "Declining Return Migration From the United States to Mexico in the Late-2000s Recession: A Research Note," Demography, 2011, 48 (3), 10491058 .

Suzuki, Masao, "Success Story? Japanese Immigrant Economic Achievement and Return Migration, 19201930," The Journal of Economic History, 1995, 55 (4), 889-901. 
Thom, Kevin, "Repeated Circular Migration: Theory and Evidence from Undocumented Migrants," August 2010. Working Paper.

Warren, Robert and Jennifer Marks Peck, "Foreign-born emigration from the United States: 1960 to 1970," Demography, 1980, 17 (1), 71-84.

Willcox, Walter F., International Migrations, Volume I: Statistics, NBER, 1929.

Williamson, Jeffrey G., "The Evolution of Global Labor Markets since 1830: Background Evidence and Hypotheses," Explorations in Economic History, 1995, 32, 141-196. 